\title{
Study on Galloping Oscillation of Iced Twin Bundle Conductors considering the Effects of Variation of Aerodynamic and Electromagnetic Forces
}

\author{
Chuan Wu, ${ }^{1}$ Zhongfei Ye, ${ }^{1}$ Bo Zhang, ${ }^{1}$ Yong Pan, ${ }^{1}$ Qing Li, ${ }^{1}$ and Bo Yan ${ }^{2}$ \\ ${ }^{1}$ State Grid Henan Electric Power Research Institute \& State Grid Key, \\ Laboratory of Power Transmission Line Galloping Prevention and Control Technology, Zhengzhou 450052, China \\ ${ }^{2}$ College of Aerospace Engineering, Chongqing University, Chongqing 400044, China
}

Correspondence should be addressed to Bo Yan; boyan@cqu.edu.cn

Received 24 November 2019; Revised 13 May 2020; Accepted 16 June 2020; Published 26 July 2020

Academic Editor: Sundararajan Natarajan

Copyright (c) 2020 Chuan Wu et al. This is an open access article distributed under the Creative Commons Attribution License, which permits unrestricted use, distribution, and reproduction in any medium, provided the original work is properly cited.

Due to the occurrence of whole-span and subspan vibration at the same time during the galloping of the iced bundle conductors, the distance between the subconductors changes, resulting in the variation of the aerodynamic parameters for the leeward subconductors. The existing conventional studies usually only consider the whole-span galloping, ignoring the relative motion and the electromagnetic force between the subconductors. Based on considering the above two factors at the same time, a new numerical simulation method to study the galloping behaviors of the iced conductors is presented. Then, the galloping behaviors of the iced twin bundle conductors' transmission line with different current intensity, initial wind attack angle, and spacer layout are studied. The galloping oscillation behaviors include time histories of vibration displacements, mode, amplitude, frequency, motion traces, and the distance between two subconductors. The simulation results showed that the whole-span and subspan vibration appear at the same time during galloping oscillation and two subconductors may collide with each other when affected by the varying electromagnetic and aerodynamic forces. The effects of varying electromagnetic and aerodynamic forces on galloping behavior cannot be ignored. The new method presented in this work can contribute to the galloping study of the iced bundle conductors.

\section{Introduction}

Galloping is one of the most important factors to affect the safety of iced bundle conductor transmission lines [1]. The whole-span and subspan vibration of bundle conductors may occur at the same time when galloping takes place. It may cause rupture of the conductors, collision between subconductors, and collapse of the towers, endangering the safe operation and inflicting large economic loss. Therefore, in order to restrain the galloping of conductors more effectively, it is necessary to understand the galloping characteristics of bundle conductors more accurately. This paper mainly focuses on the galloping oscillation of the iced twin bundle conductor.

Many scholars have conducted a lot of research [1-20] on galloping of the iced bundle conductors transmission lines. On the basis of ignoring the difference of aerodynamic characteristics for all subconductors, Zhang et al. [5] simplified the bundle conductor as a single conductor to analyze the galloping characteristics. Talib et al. [6] proposed a new galloping simulation model of transmission lines based on the energy approach and studied the typical galloping characteristics of lines. Hu et al. [7], Yan et al. [8] and Zhou et al. [9] studied the characteristics of galloping frequency, amplitude, and trajectory of the quad and eight bundle conductors with considering the aerodynamic characteristic differences of each subconductor. Lu et al. [10] studied the aerodynamic parameters of crescent-shaped and D-shaped iced quad bundle conductors by the wind tunnel test. On this basis, the influence of wind speed, ice thickness, conductor type, bundle spacing, and bundle number on conductor 
galloping is studied. Lou et al. [11] studied the aerodynamic characteristics of eight bundle conductors with torsion freedom by the wind tunnel test and the influence of torsion freedom on galloping characteristics. Matsumiya et al. [4] simplified all conductors as one group and each subconductor independently to study the galloping characteristics of the conductor. Compared with the wind tunnel test results, it is found that simplifying each subconductor into a group can more accurately simulate the galloping of the research conductor. Besides, there are some research studies $[1,12-17]$ on the wake-induced vibration of the bare bundle conductor using 2-D or simplified 3-D models, in which the aerodynamic characteristics of the subconductors varying with their relative position between subconductors were considered. Overall, the aerodynamic coefficients of the iced sub-conductors changing with their relative position and electromagnetic forces are ignored in most studies on galloping of iced bundle conductor transmission lines.

In order to study galloping of iced twin bundle conductor lines, the aerodynamic characteristics of the subconductors varying with the wind attack angle and the relative position between two subconductors are numerically simulated by the FLUENT software. The numerical simulation method based on the user-defined subroutine UEL in ABAQUS software for galloping oscillation of iced twin bundle conductor lines is presented. This method considered not only the variation of aerodynamic forces with both wind attack angle and the relative position between subconductors but also the variation of electromagnetic forces with the relative position. The galloping oscillation behaviors of iced twin bundle conductors under different parameters are numerically investigated. The new method presented in this work can contribute to the galloping study of the iced bundle conductors and the development of antigalloping techniques.

\section{Aerodynamic Characteristics of Iced Twin Bundle Conductors}

2.1. Wind Tunnel Test Verification for the Numerical Method. Cai et al. [18] adopted a numerical simulation method by the fluid dynamic software FLUENT to analyze the aerodynamic characteristics of a quad bundle conductor covered with crescent-shaped ice in detail. In this study, it is mentioned that the aerodynamic characteristics of an iced transmission line mainly depend on its cross-sectional shape, suggesting that the 2-D model can be used to study the aerodynamic characteristics of the line. Thus, this method adopted in Cai's study was used in this paper.

To verify the numerical method, air flow around a typical iced quad bundle conductor was simulated and the aerodynamic coefficients obtained by the numerical method were compared with those by the wind tunnel test carried out by the research group. The quad bundle conductor is 4XLGJ-400/50. The subconductor diameter is $27.6 \mathrm{~mm}$, and the distance between each pair of adjacent subconductors is $450 \mathrm{~mm}$. The thicknesses of the crescent-shaped ice are assumed to be $12 \mathrm{~mm}$. The wind velocity is $12 \mathrm{~m} / \mathrm{s}$. The numerical model is illustrated in Figure 1. According to
Figure 1, the center line of the bundle conductor cross section is parallel to the $Y$-axis. The angle between the center line and the wind direction is defined as the initial wind attack angle $\alpha$. The angle between the long axis of the iced conductor cross section and the center line is defined as the initial ice angle, which is assumed as 0 degree in this paper. The cross-sectional dimension of the bundle conductor is about $500 \mathrm{~mm} \times 500 \mathrm{~mm}$. The size of the domain for flow analysis is set to be about 25 times of the bundle cross section, i.e., $12 \mathrm{~m} \times 12 \mathrm{~m}$. The Spalart-Allmaras turbulent model, SIMPLE algorithm, and three-order QUICK scheme are applied in the numerical method $[18,19]$. Moreover, a time increment of $0.001 \mathrm{~s}$ is used in the transient analysis model.

The aerodynamic coefficients of the iced quad bundle conductor were measured by wind tunnel tests in China Aerodynamics Research and Development Center. A segment model of real conductor covered with artificial crescent-shaped ice was employed. The characteristics of the iced quad bundle conductor used in the wind tunnel tests are similar to those used in the numerical model. The length of the conductor is $700 \mathrm{~mm}$. The subconductor models are installed vertically between two parallel circular wood plates as displayed in Figure 2. The lift, drag, and moment forces are obtained by strain balances, which are installed inside the hollow of each iced subconductor model. The aerodynamic parameters of each iced subconductor at different wind attack angles in the range of $-180^{\circ} \sim 180^{\circ}$ were obtained by the wind tunnel test.

The average lift, drag, and moment coefficients of the iced quad bundle conductor varying with wind attack angle determined by both the numerical simulation and wind tunnel test are shown in Figure 3. According to the galloping mechanism, the conductor galloping is mainly related to the slope of lift and torque coefficients. It can be seen that the laws and slopes of the aerodynamic coefficients with wind attack angle obtained by the wind tunnel test and by the numerical simulation are very similar. The difference between the aerodynamic parameters obtained by the wind tunnel test and those obtained by the numerical simulation is acceptable. Therefore, the numerical method, which has been used in reference [18], can be used to study the aerodynamic coefficients of an iced bundle conductor.

\subsection{Simulation of the Air Flow around an Iced Twin Bundle} Conductor. When galloping occurs, the vibration of each iced subconductor may be different. In this case, the aerodynamic characteristics of the iced subconductors may vary with the wind attack angle and the relative position between subconductors. However, for the iced bundle conductors with more than two subconductors, the aerodynamic characteristics of subconductors, especially the leeward subconductors in the wake, may be extremely complicated. That is because interferences of the flows exist between subconductors. Thus, this study mainly focuses on the aerodynamic characteristics of iced twin bundle conductors. 


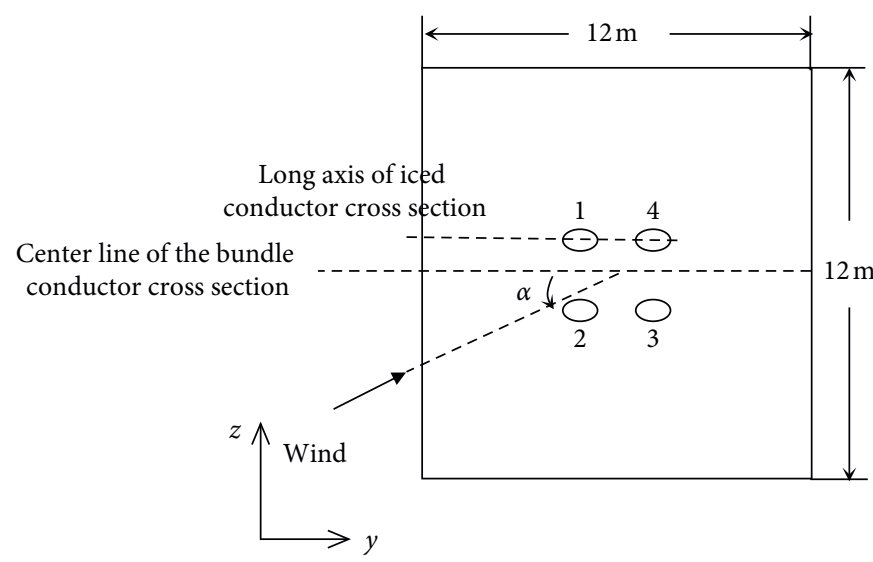

(a)

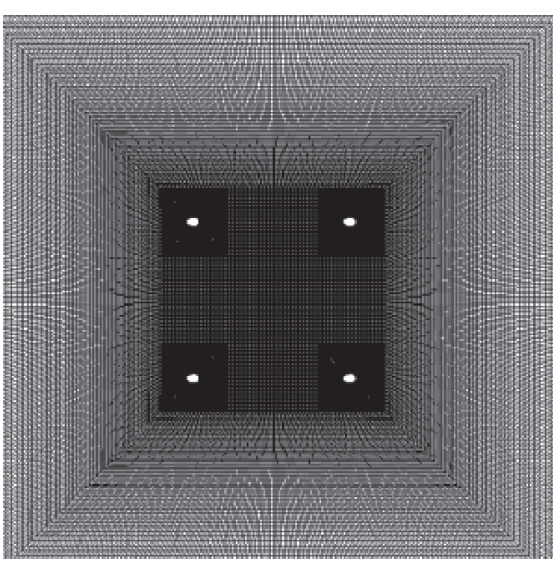

(b)

Figure 1: Numerical model of an iced quad bundle conductor: (a) simulation model and (b) mesh model.

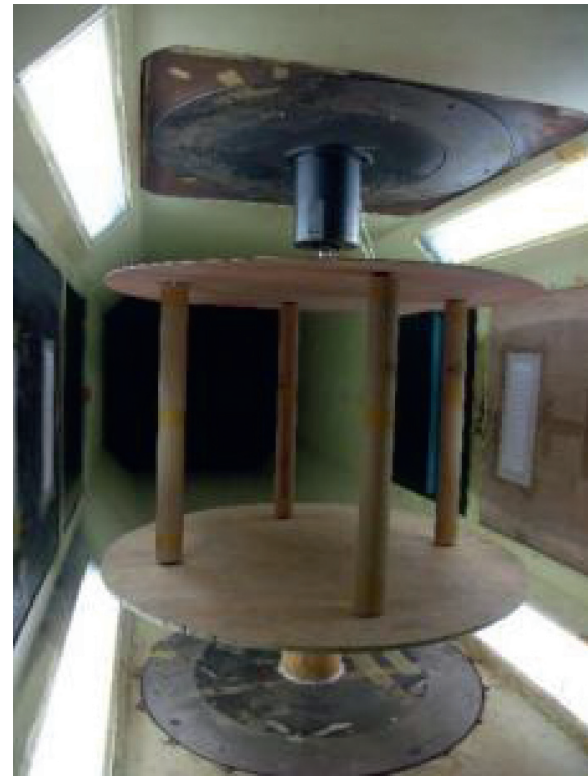

(a)

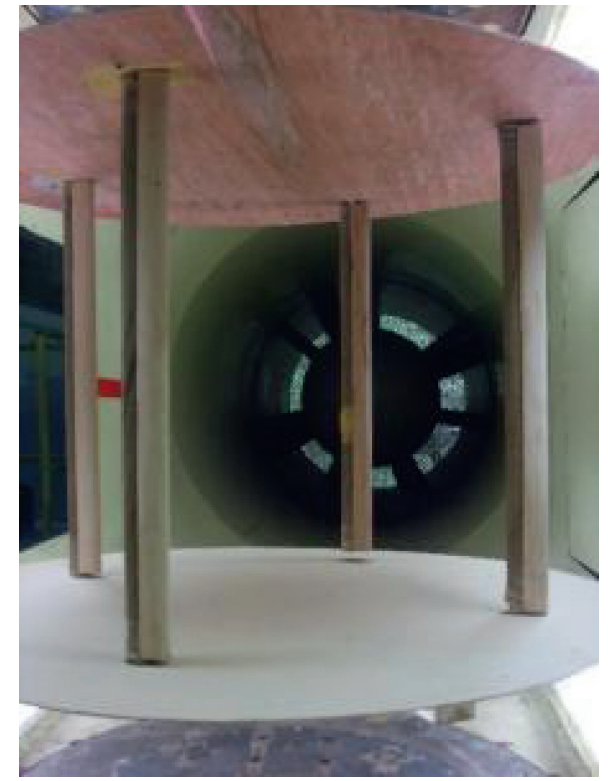

(b)

Figure 2: Wind tunnel test model of an iced quad bundle conductor.

Previous researches [1, 12-17] mainly studied the wake influence of the windward subconductor on the leeward subconductor of a bare twin bundle conductor. The relative position between bare subconductors is the main factor which influences the aerodynamic characteristics, whereas both the relative position and the wind attack angle are important for the iced subconductors.

In the numerical model, the horizontal distance is in the range of $4 D \sim 30 D$ with increment $2 D$ and vertical distance in the range of $-5 D \sim 5 D$ with increment $1 D$ between two subconductors. Besides, the range of the wind attack angle is from $-180^{\circ}$ to $180^{\circ}$ with an increment $5^{\circ}$. There are 6048 numerical models need to be calculated by considering the structure symmetry. The wake influence region and numerical model of an iced twin bundle conductor is shown in Figure 4. The type of the conductor is 2XLGJ-400/50.
Each subconductor has a diameter of $27.6 \mathrm{~mm}$. The thicknesses of the crescent-shaped ice are assumed to be $12 \mathrm{~mm}$. The wind is assumed to be smooth, and its velocity is $12 \mathrm{~m} / \mathrm{s}$.

The velocity contours of the air flow around the iced twin bundle conductor with a wind attack angle of $0^{\circ}$ in the case of $Z=10 D$ and $Y=0 D, 2 D, 3 D$ and $5 D$ are shown in Figure 5, respectively. It can be seen from Figure 5 that vortex shedding takes place obviously. As $Y=0$, the wake of the windward subconductor affects the inflow of the leeward subconductor seriously. As $Y$ increases, the wake influence of the flow around the leeward subconductor decreases. As $Y=5 D$, the air flow around leeward subconductor is affected by the wake of the windward subconductor slightly as illustrated in Figure 5(d). In this case, the aerodynamic lift and drag coefficients of the windward conductor are 0.389 and 

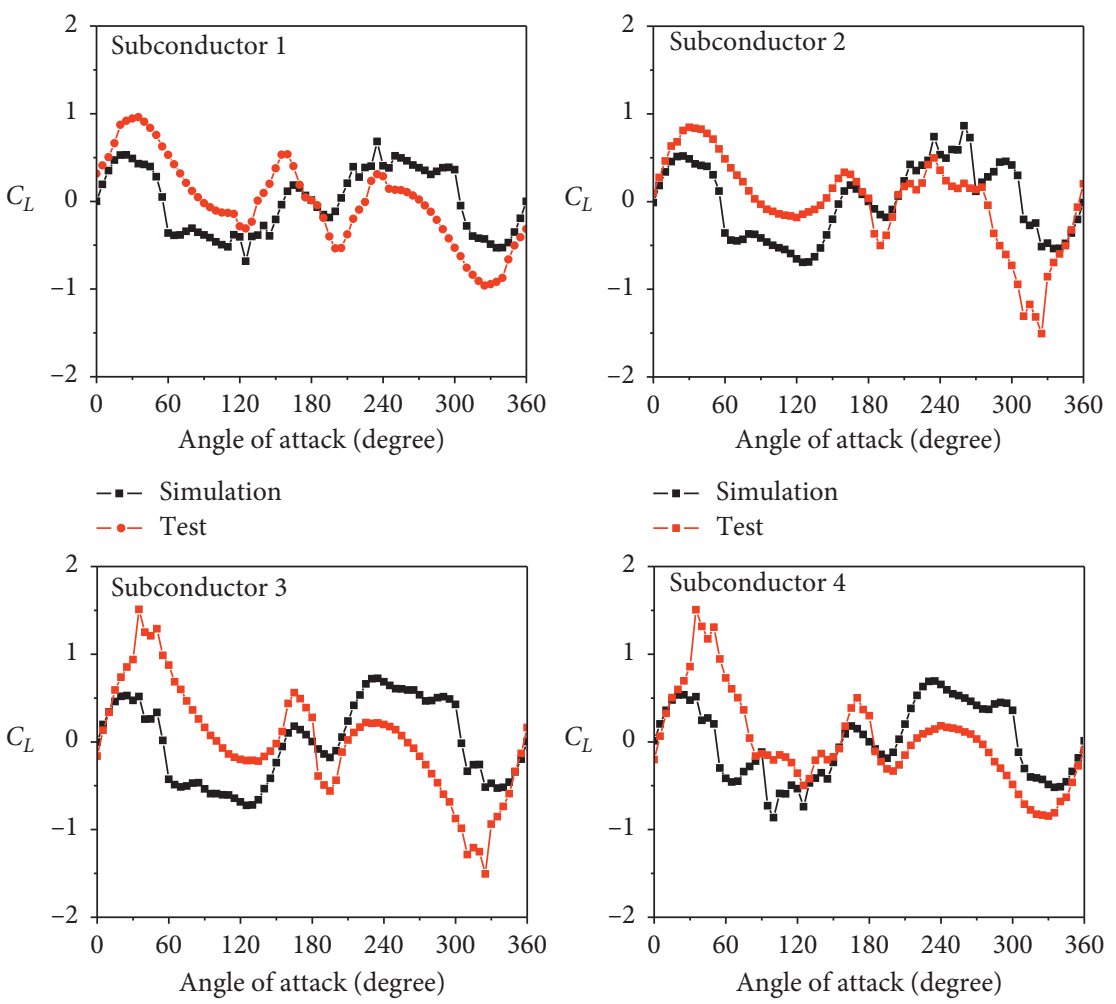

--- Simulation

-- Simulation

- - Test

- - Test

(a)
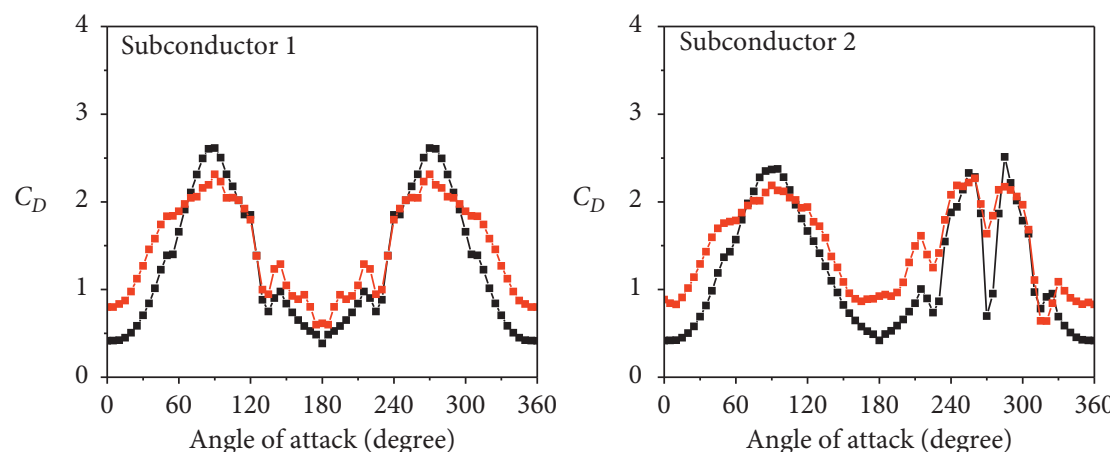

-- Simulation

- - Test

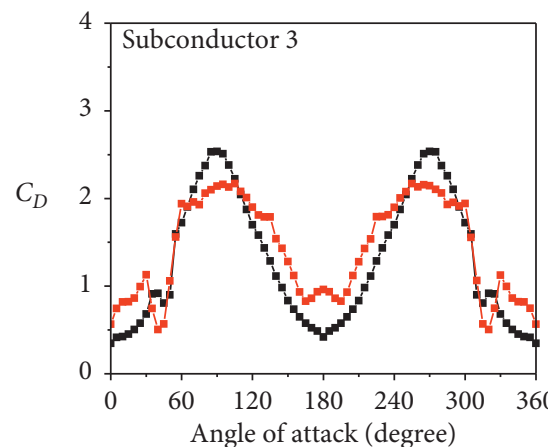

-- Simulation

$-\because-$ Test

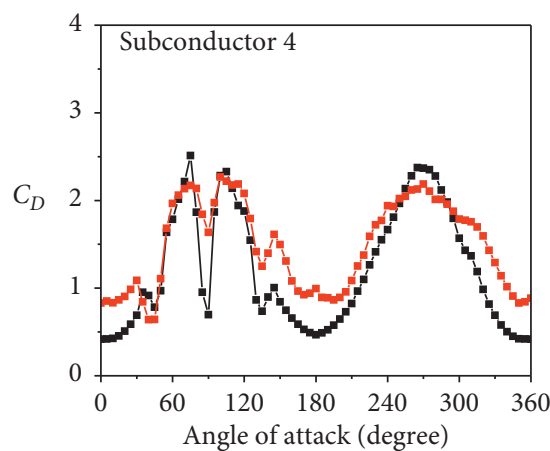

-- Simulation

- - Test

-- Simulation

- - Test

(b)

Figure 3: Continued. 

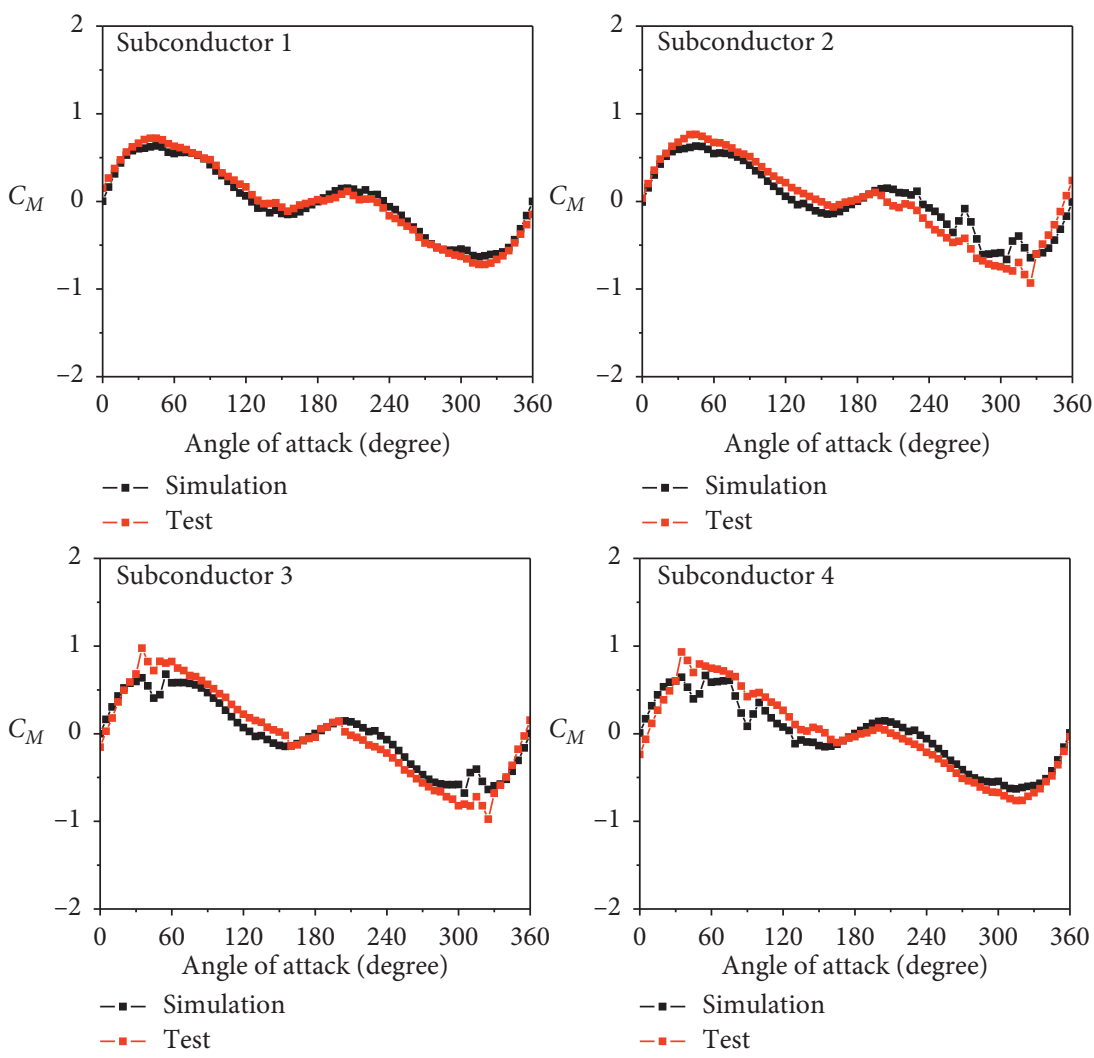

(c)

Figure 3: Aerodynamic coefficients of the iced quad bundle conductor varying with wind attack angle (wind velocity: $12 \mathrm{~m} / \mathrm{s}$ ): (a) lift coefficients, (b) drag coefficients, and (c) moment coefficients.

0.662 , and those of the leeward conductor are 0.388 and 0.661 , respectively.

\subsection{Aerodynamic Coefficients of the Iced Subconductors.} The variations of the lift, drag, and moment coefficients of the iced subconductors with the wind attack angle in the case of $Y=0 D$ and $Z=4 D, 8 D, 16 D, 26 D$, and $30 D$ are illustrated in Figure 6. It can be seen that the wake of the windward subconductor impacts on both subconductors as the horizontal distance is $4 D$ and the effect of wake on the leeward subconductor is more obvious than that on the windward subconductors. At the same wind attack angle, the aerodynamic coefficients of two subconductors become gradually stable with the increase in the horizontal distance between two subconductors. Moreover, the aerodynamic coefficients change significantly with the variation of the wind attack angles at the same horizontal and vertical distance between two subconductors. It is noted that all aerodynamic coefficients in the cases of the horizontal distance in the range of $4 D \sim 30 D$, the vertical distance in the range of $--D \sim 5 D$, and the wind attack angle in the range of $-180^{\circ} \sim 180^{\circ}$ are simulated. The coefficients under different horizontal distances are given in Figure 6.

\section{Numerical Simulation Method for Galloping Oscillation}

The galloping of iced twin bundle conductor transmission lines is studied by using the UEL subroutine of ABAQUS software. The method is described in detail in the author's previous research [20]. In this method, the corresponding electromagnetic and aerodynamic forces of the conductor are applied by reading the displacement and angle of the conductor in real time. The application mode of electromagnetic force is described as in the previous research $[20,21]$. Besides, the aerodynamic force application mode of the conductor is described as follows.

The aerodynamic forces of each subconductor can be obtained by

$$
\begin{gathered}
F_{L}=\frac{1}{2} \rho U^{2} d C_{L}(\alpha, Y, Z), \\
F_{D}=\frac{1}{2} \rho U^{2} d C_{D}(\alpha, Y, Z), \\
F_{M}=\frac{1}{2} \rho U^{2} d C_{M}(\alpha, Y, Z),
\end{gathered}
$$

where the wind attack angle $a$ is approximated by 

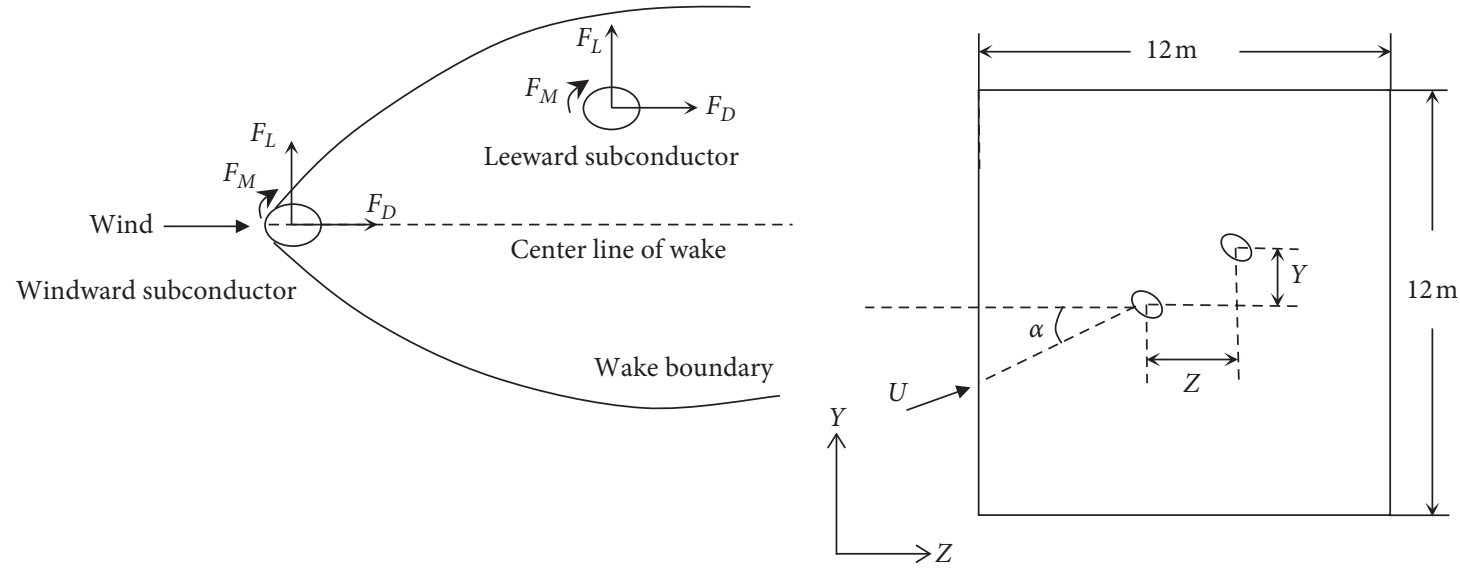

(a)

(b)

FIGURE 4: The influence region of iced twin bundle conductors and the numerical model: (a) wake influence zone and (b) a numerical model for the relative position between two subconductors.

$$
a=\theta-\left(\frac{R \theta+V}{U}\right) .
$$

The variables $\theta, \dot{\theta}$, and $\dot{V}$ represent the torsional angle, torsional angular velocity, wind velocity, and vertical velocity of the iced conductors obtained by the numerical simulation, respectively. In addition, $R$ is the so-called characteristic radius, which is defined as the radius of each subconductor.

As described above, there are drag, lift, and moment on the two iced subconductors at the same time, and the aerodynamic coefficients $C_{L}(\alpha, Y, Z), C_{D}(\alpha, Y, Z)$, and $C_{M}$ $(\alpha, Y, Z)$ depend on its wind attack angle and the relative position between two subconductors during galloping. The aerodynamic forces of each subconductor at any position can be obtained by interpolation in the aerodynamic curves, as shown in Section 2.3.
The interpolation method of the aerodynamic coefficients is simply introduced as follows. Due to the coefficients varying with wind attack angle and horizontal and vertical distance between two subconductors, the threedimensional hexahedral element is adopted for interpolation calculation, as shown in Figure 7. Linear interpolation is used in all directions. The aerodynamic coefficients for all nodes of the element are obtained by the numerical simulation method. The aerodynamic coefficients of an interior point $N$ can be obtained as follows. When the wind attack angle $\alpha_{0}$ is $\alpha=<\alpha_{0}<\alpha+1$, the horizontal distance $Z_{0}$ is $Z=<Z_{0}<Z+1$, vertical distance $Y_{0}$ is $Y=<Y_{0}<Y+1$, the projection of point $N$ in ABCD plane is $N_{Z}$, and that in the EFGH plane is $N_{Z+1}$. Thus, the aerodynamic coefficients $C_{N_{Z}}$ of point $N_{Z}$ in the ABCD plane can be expressed as follows:

$$
\begin{aligned}
C_{N_{Z Y}} & =C_{A}+\left(C_{B}-C_{A}\right) \frac{\left(\alpha_{0}-\alpha\right)}{\left(\alpha_{0}+\Delta \alpha-\alpha_{0}\right)}, \\
& =C_{A}+\left(C_{B}-C_{A}\right) \frac{\left(\alpha_{0}-\alpha\right)}{\Delta \alpha}, \\
C_{N_{Z(Y+\Delta Y)}} & =C_{D}+\left(C_{C}-C_{D}\right) \frac{\left(\alpha_{0}-\alpha\right)}{\Delta \alpha}, \\
C_{N_{Z}} & =C_{N_{Z Y}}+\left(C_{N_{Z(Y+\Delta Y)}}-C_{N_{Z Y}}\right)\left(Y_{0}-Y\right), \\
& =C_{A}+\left(C_{B}-C_{A}\right) \frac{\left(\alpha_{0}-\alpha\right)}{\Delta \alpha}+\left(C_{D}-C_{A}+\left(C_{C}+C_{A}-C_{D}-C_{B}\right) \frac{\left(\alpha_{0}-\alpha\right)}{\Delta \alpha}\right) \frac{\left(Y_{0}-Y\right)}{\Delta Y} .
\end{aligned}
$$

Similarly, the aerodynamic coefficients $C_{N_{Z+\Delta Z}}$ of point $N_{Z+1}$ in the EFGH plane can be shown as follows: 

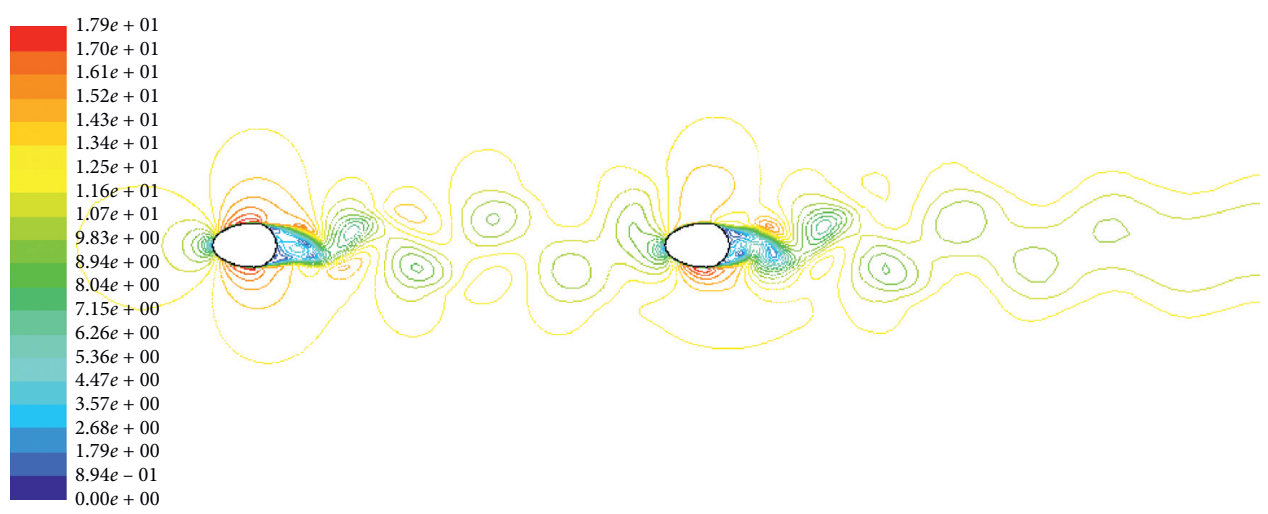

(a)
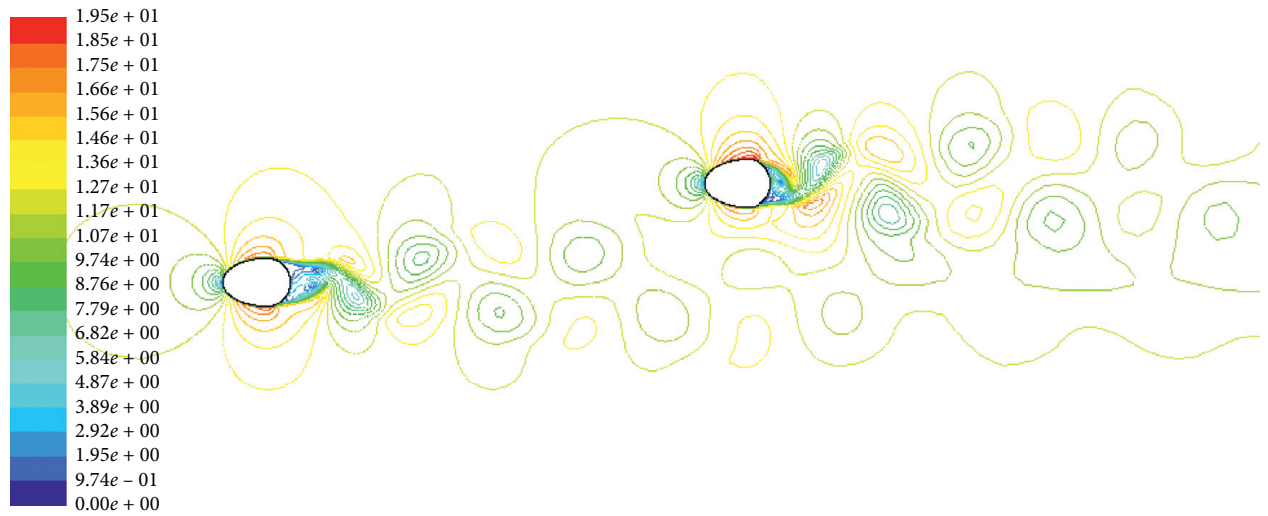

(b)
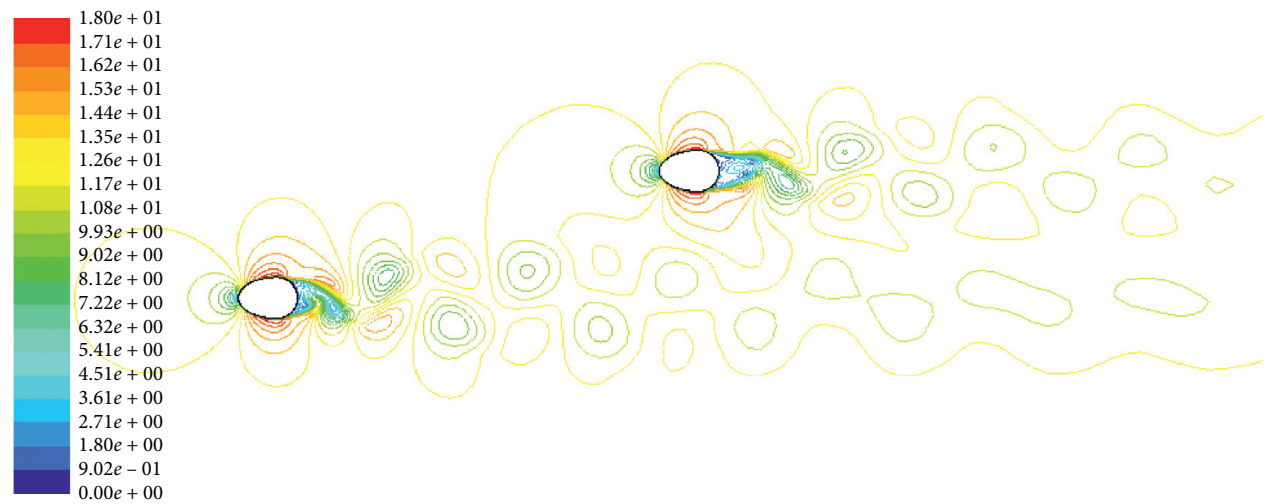

(c)
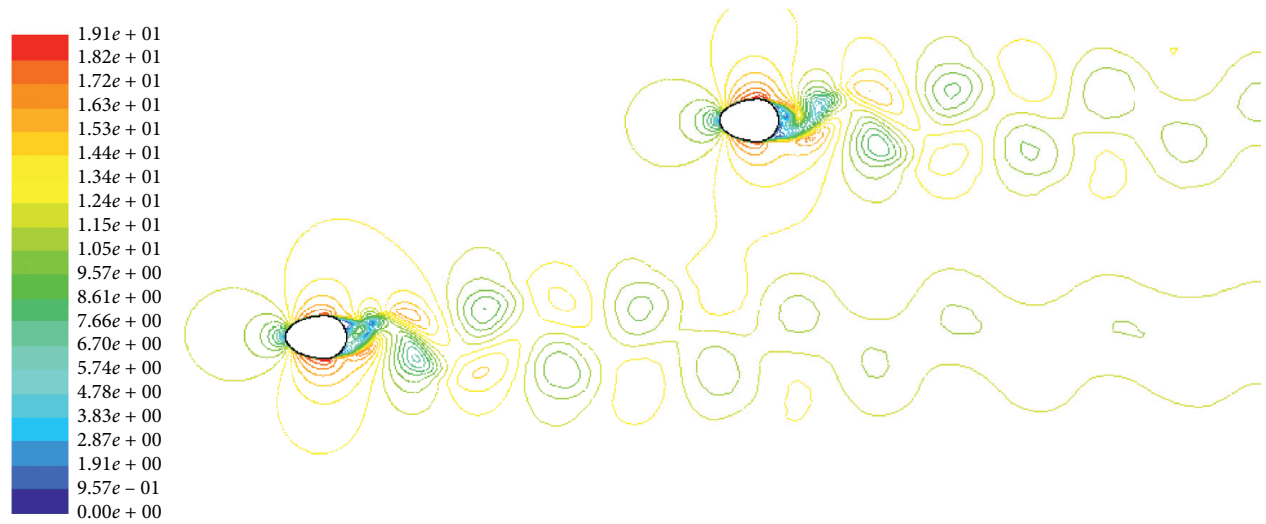

(d)

FiguRE 5: Velocity contours of air flow around an iced twin bundle conductor $\left(\alpha=0^{\circ}\right.$ ): (a) $Z=10 D$ and $Y=0$. (b) $Z=10 D$ and $Y=2 D$. (c) $Z=10 D$ and $Y=3 D$. (d) $Z=10 D$ and $Y=5 D$. 

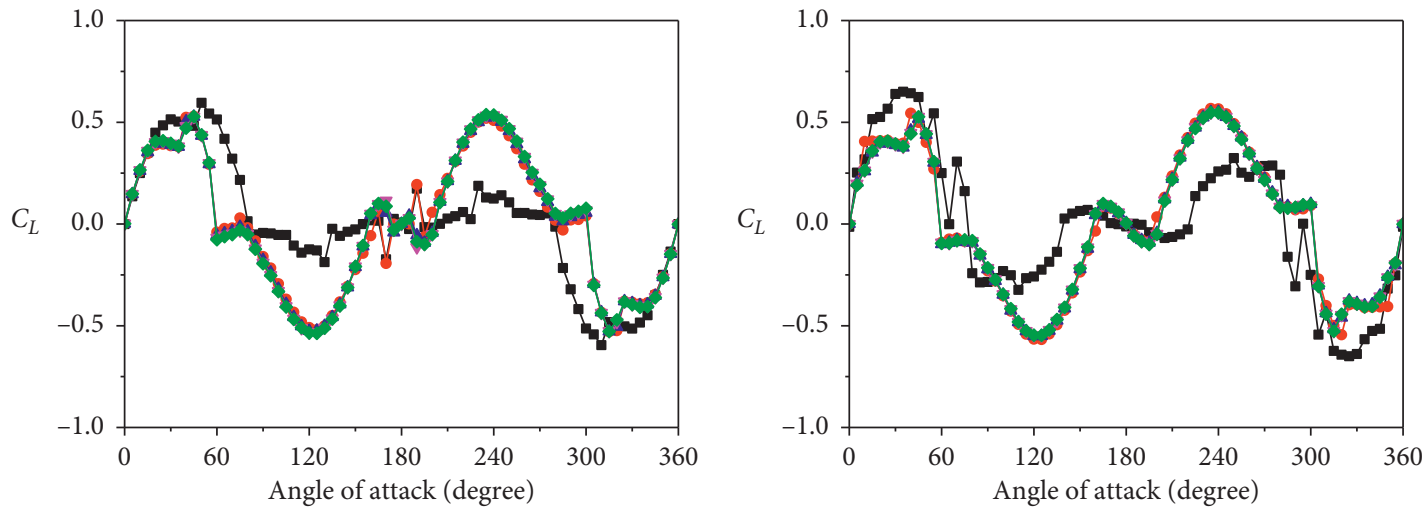

$$
\begin{array}{ll}
\rightarrow Z=4 D & \rightarrow Z=26 D \\
\rightarrow Z=8 D & \rightarrow Z=30 D \\
\smile Z=16 D &
\end{array}
$$

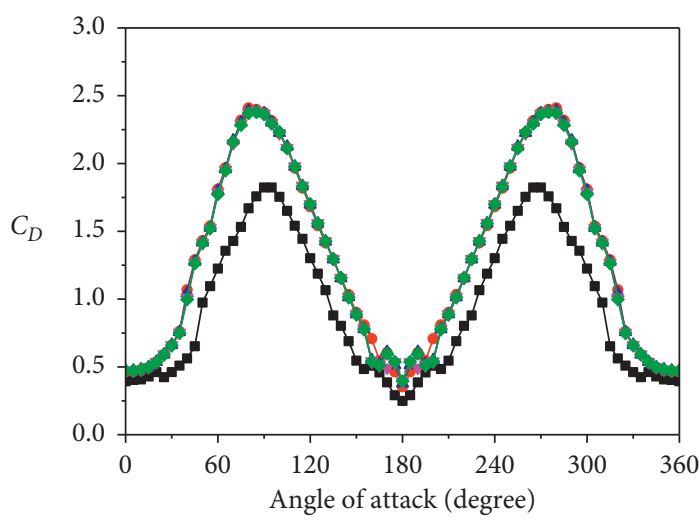

$$
\begin{array}{ll}
\rightarrow Z & =4 D \\
\rightarrow Z=8 D & \rightarrow Z=26 D \\
\leftarrow Z=16 D &
\end{array}
$$

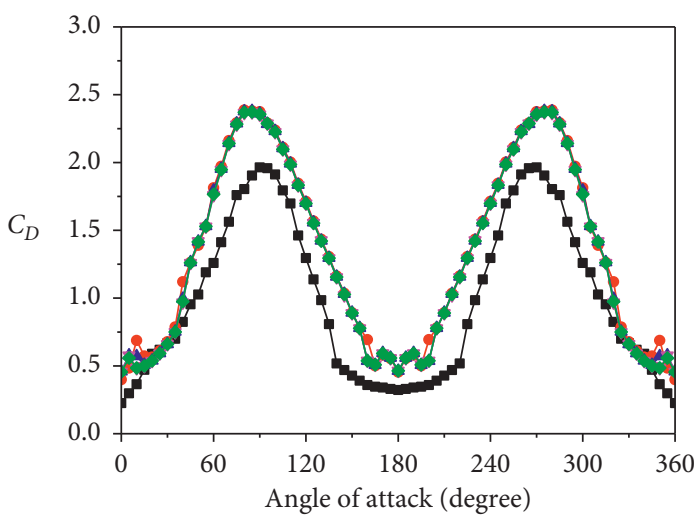

$$
\begin{array}{ll}
\rightarrow Z=4 D & \rightarrow Z=26 D \\
\rightarrow Z & =8 D \\
\bullet Z & =16 D
\end{array}
$$

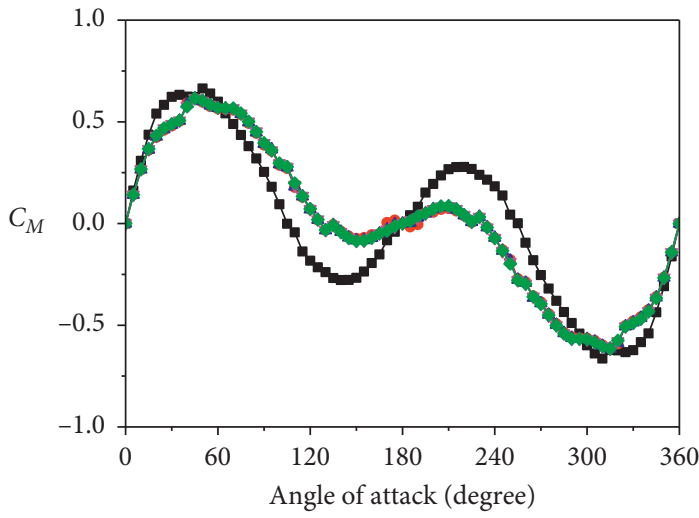

$$
\begin{array}{ll}
\rightarrow Z=4 D & \rightarrow Z=26 D \\
\rightarrow Z=8 D & \rightarrow Z=30 D \\
\hookrightarrow Z=16 D &
\end{array}
$$

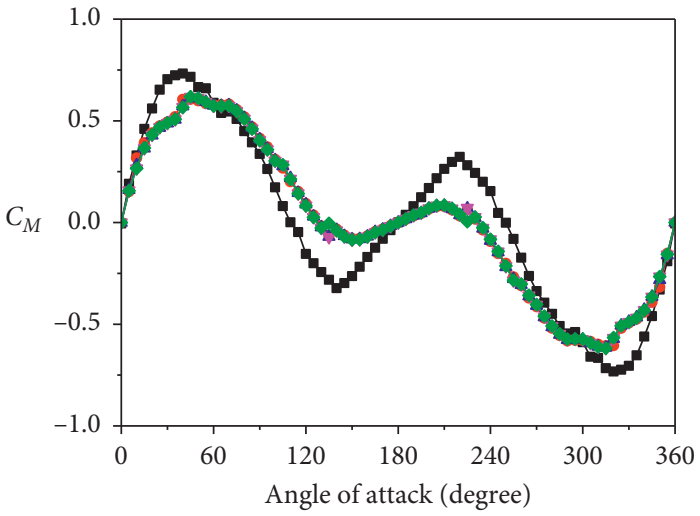

$$
\begin{array}{ll}
\rightarrow Z=4 D & \rightarrow Z=26 D \\
\rightarrow Z=8 D & \rightarrow Z=30 D
\end{array}
$$

(a)

$$
\begin{aligned}
& \rightarrow Z=4 D \\
& \rightarrow Z=8 D \\
& \multimap Z=16 D
\end{aligned}
$$

(b)

Figure 6: Aerodynamic coefficients of iced subconductors varying with wind attack angle $Y=0 D$ : (a) subconductor 1 and (b) subconductor 2 . 


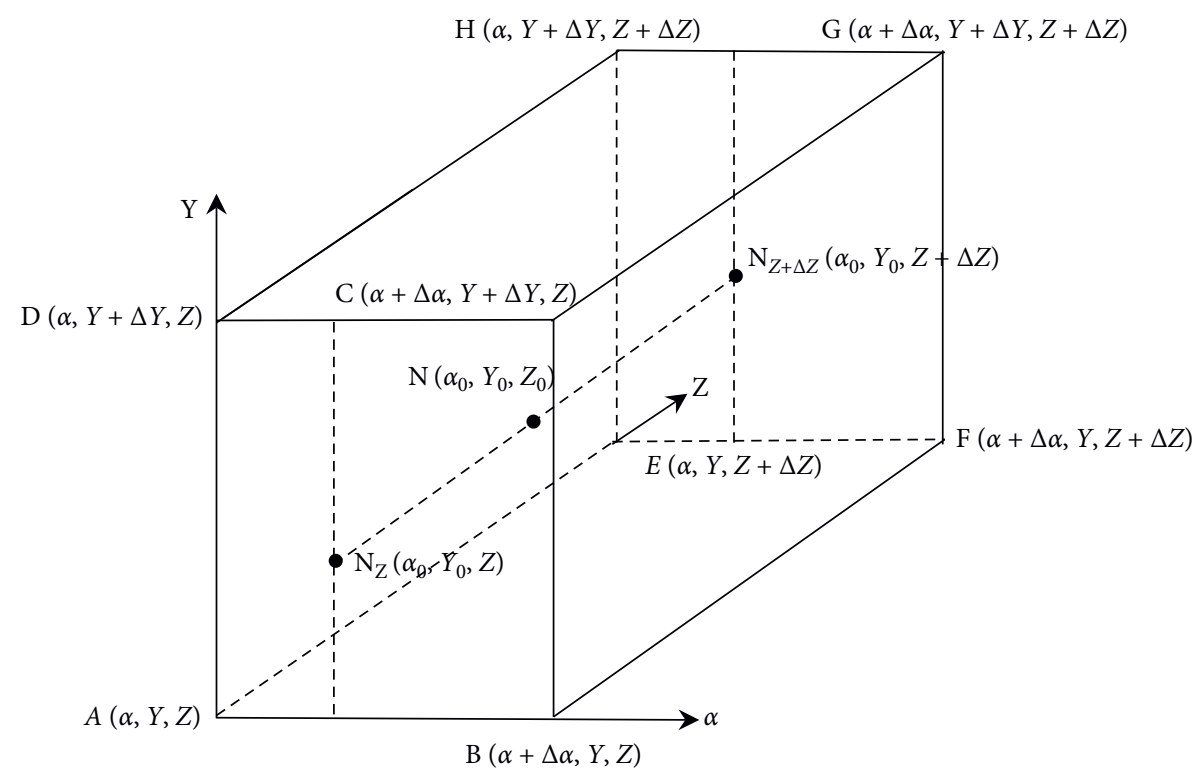

FIGURE 7: Simplified interpolation element of the aerodynamic coefficients.

$$
\begin{aligned}
C_{N_{Z+\Delta Z}} & =C_{N_{(Z+\Delta Z) Y}}+\left(C_{N_{(Z+\Delta Z)(Y+\Delta Y)}}-C_{N_{(Z+\Delta Z) Y}}\right)\left(Y_{0}-Y\right) \\
& =C_{E}+\left(C_{F}-C_{E}\right) \frac{\left(\alpha_{0}-\alpha\right)}{\Delta \alpha}+\left(C_{H}-C_{E}+\left(C_{G}+C_{E}-C_{H}-C_{F}\right) \frac{\left(\alpha_{0}-\alpha\right)}{\Delta \alpha}\right) \frac{\left(Y_{0}-Y\right)}{\Delta Y} .
\end{aligned}
$$

The aerodynamic coefficients $C_{N}$ of point $N$ can be obtained by the interpolation between points $N_{Z}$ and $N_{Z+1}$ and can be represented as follows:

$$
\begin{aligned}
C_{N}= & C_{N_{Z}}+\left(C_{N_{Z+\Delta Z}}-C_{N_{Z}}\right)\left(Z_{0}-Z\right) \\
= & C_{A}+\left(C_{B}-C_{A}\right) \frac{\left(\alpha_{0}-\alpha\right)}{\Delta \alpha}+\left(C_{D}-C_{A}+\left(C_{C}+C_{A}-C_{D}-C_{B}\right) \frac{\left(\alpha_{0}-\alpha\right)}{\Delta \alpha}\right) \frac{\left(Y_{0}-Y\right)}{\Delta Y} \\
& +\left(C_{E}-C_{A}+\left(C_{F}+C_{A}-C_{E}-C_{B}\right) \frac{\left(\alpha_{0}-\alpha\right)}{\Delta \alpha}+\left(C_{H}+C_{A}-C_{E}-C_{D}+\left(C_{G}+C_{E}+C_{D}+C_{B}-C_{H}-C_{F}-C_{C}-C_{A}\right)\right.\right. \\
& \left.\left.\frac{\left(\alpha_{0}-\alpha\right)}{\Delta \alpha}\right) \frac{\left(Y_{0}-Y\right)}{\Delta Y}\right) \frac{\left(Z_{0}-Z\right)}{\Delta Z} .
\end{aligned}
$$

The wind attack angle and the horizontal and vertical distance between two subconductors can be obtained based on their rotation angles and displacements at current time by the user-defined subroutine UEL. The aerodynamic coefficients and forces on each subconductor can be determined by equations (5) and (1), respectively. It is noted that the $0.5 \%$ of critical damping ratio suggested in the literature [22] is adopted in this paper.

\section{Galloping Oscillation Behavior of Iced Twin Bundle Conductors}

4.1. Numerical Models of Typical Lines. In this paper, twin bundle conductor 2XLGJ-400/50 with $200 \mathrm{~m}$ span length is taken as the research object. The initial tension of the conductor is $28.899 \mathrm{kN}$, and the physical parameters of conductor are shown in Table 1. Three spacers, each of which 
TABLE 1: Geometrical and physical parameters of conductor LGJ-400/50.

\begin{tabular}{lcccc}
\hline Diameter $(\mathrm{mm})$ & Cross sectional area $\left(\mathrm{mm}^{2}\right)$ & Mass per unit length $(\mathrm{kg} / \mathrm{m})$ & Young's modulus $(\mathrm{GPa})$ & Poisson's ratio \\
\hline 27.6 & 451.55 & 1.511 & 69.0 & 0.3 \\
\hline
\end{tabular}

TABLE 2: Subspan length of the $200 \mathrm{~m}$ span line with different spacer layouts.

\begin{tabular}{lccccc}
\hline \multirow{2}{*}{ Spacer layout } & \multirow{2}{*}{ Span length $(\mathrm{m})$} & \multicolumn{3}{c}{ Subspan length $(\mathrm{m})$} \\
& & Subspan 1 & Subspan 2 & Subspan 3 & Subspan 4 \\
\hline Symmetric & \multirow{2}{*}{200} & 33.33 & 66.67 & 66.67 & 33.33 \\
Unsymmetric & \multirow{2}{*}{200.33} & 70 & 53.33 \\
\hline
\end{tabular}

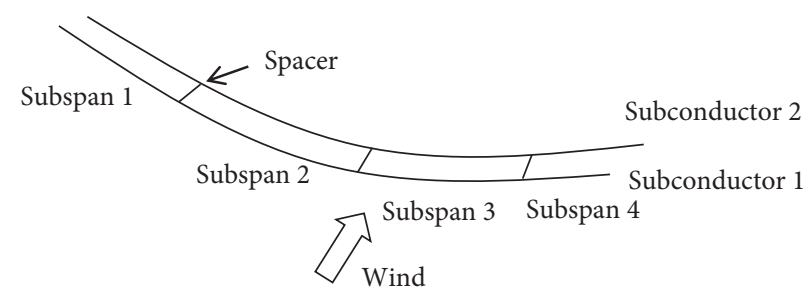

FIgURE 8: Numerical model of a twin bundle conductor with three spacers.

TABLE 3: Global natural modes and frequencies of the lines.

\begin{tabular}{|c|c|c|c|}
\hline \multirow{3}{*}{ Direction } & \multirow{3}{*}{ Mode } & \multirow{2}{*}{\multicolumn{2}{|c|}{$\begin{array}{l}\text { Natural frequencies }(\mathrm{Hz}) \\
200 \mathrm{~m} \text { span line }\end{array}$}} \\
\hline & & & \\
\hline & & Symmetric spacer layout & Unsymmetric spacer layout \\
\hline \multirow{3}{*}{ In-plane } & & 0.476 & 0.475 \\
\hline & & 0.680 & 0.676 \\
\hline & & 1.026 & 1.017 \\
\hline \multirow{3}{*}{ Out-of-plane } & & 0.341 & 0.340 \\
\hline & & 0.683 & 0.678 \\
\hline & & 1.019 & 1.011 \\
\hline \multirow{3}{*}{ Torsion } & & 0.567 & 0.566 \\
\hline & & 0.847 & 0.872 \\
\hline & & 1.307 & 1.224 \\
\hline
\end{tabular}

is $4.8 \mathrm{~kg}$, are installed on the conductor in the way of symmetrical and unsymmetric distribution [23]. The specific installation method is listed in Table 2. The typical finite element model, in which the conductor and spacer are discretized by a beam element, is illustrated in Figure 8 .

4.2. Natural Frequencies and Modes of the Lines. The whole span and subspan vibration may occur at the same time during the galloping process $[1,24]$. The frequencies and modes of the iced twin bundle conductor should be obtained first due to their application in the analysis of galloping characteristics. The global natural modes and frequencies of the lines are shown in Table 3. The local frequencies and modes of the $200 \mathrm{~m}$ span line with symmetric and unsymmetric spacer layout are shown in Figure 9. It can be concluded that the global natural frequencies and modes have a small influence on the spacer layout, while the first order frequency of the local mode of the line with an unsymmetric spacer layout is less than that of the line with a symmetric spacer layout.

\subsection{Parameter Effects on Galloping Oscillation Behavior}

4.3.1. Effect of Current Intensity. For conductor LGJ-400/50, the actual running current effected by environmental conditions is smaller than the design current $741 \mathrm{~A}$. In this section, the galloping oscillation behavior of the iced $200 \mathrm{~m}$ span line with a symmetric spacer layout under the currents of $0 \mathrm{~A}, 500 \mathrm{~A}$, and $750 \mathrm{~A}$ were, respectively, numerical simulated to analyze the effect of the current intensity. The 


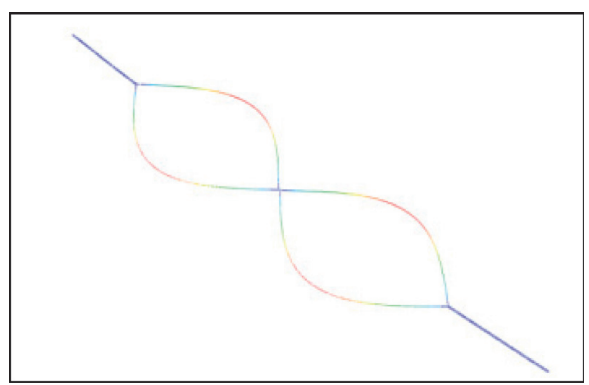

$f=1.0278 \mathrm{~Hz}$

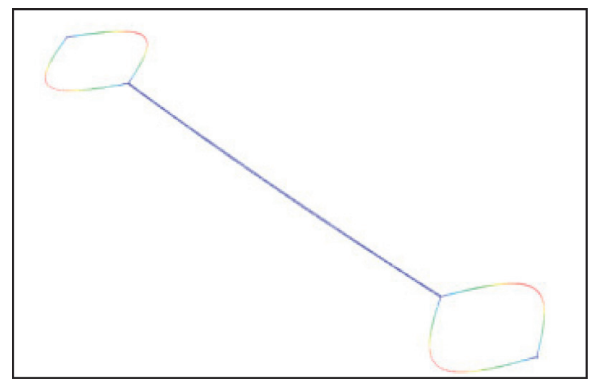

$f=2.0705 \mathrm{~Hz}$

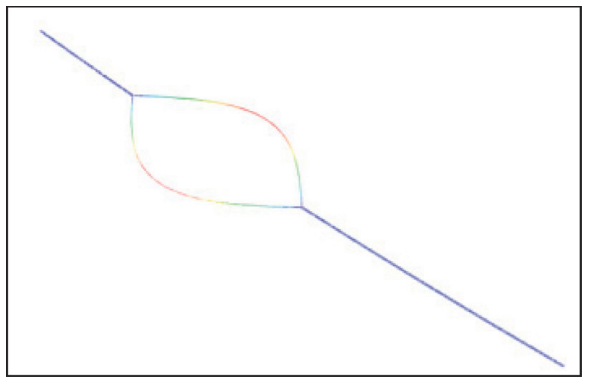

$f=0.98318 \mathrm{~Hz}$

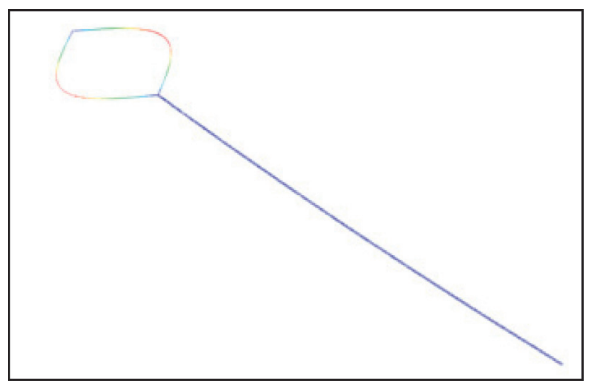

$f=1.5947 \mathrm{~Hz}$

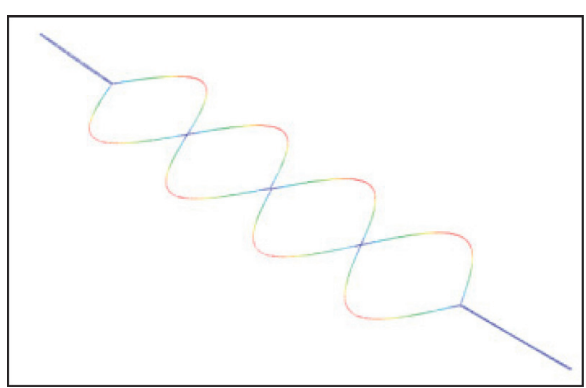

$f=2.0560 \mathrm{~Hz}$

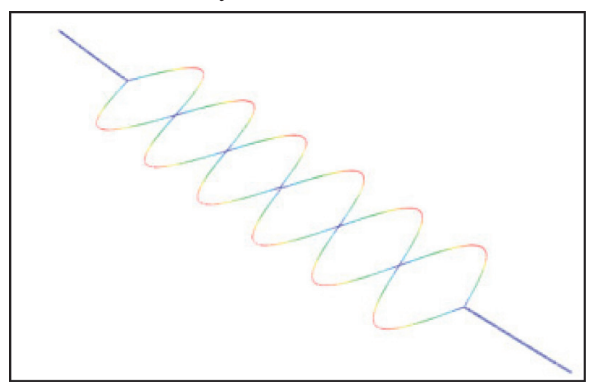

$f=3.0850 \mathrm{~Hz}$

(a)
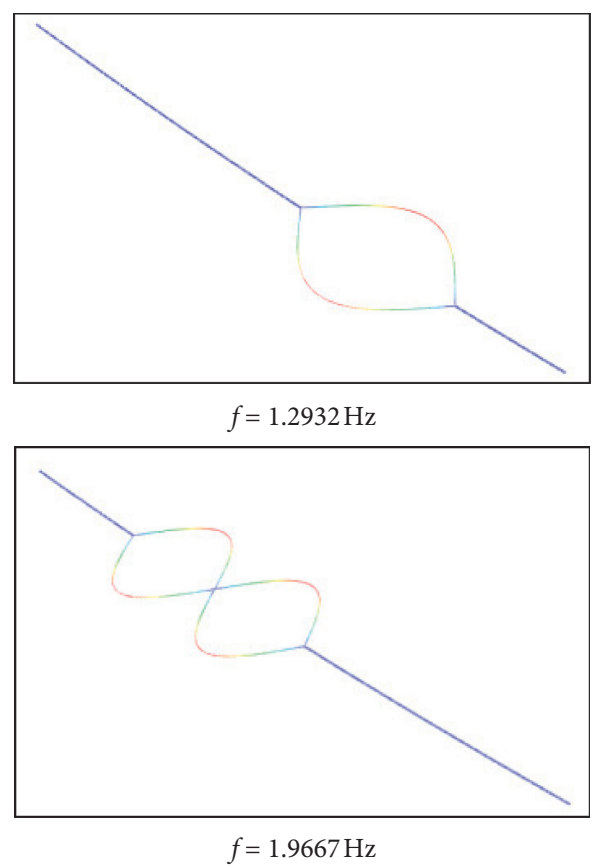

(b)

Figure 9: Typical local modes and frequencies of the lines: (a) $200 \mathrm{~m}$ span line with a symmetric spacer layout and (b) $200 \mathrm{~m}$ span line with an unsymmetric spacer layout.

ice thickness of $12 \mathrm{~mm}$, wind velocity of $12 \mathrm{~m} / \mathrm{s}$, and wind attack angle of $30^{\circ}$ were adopted in the numerical model.

Figure 10 shows the time histories of displacements and motion traces at subspan 3 midpoint under different current intensities. It can be seen that the vertical amplitude is much greater than the horizontal one, and two subconductors have the similar motion traces like a vertical ellipse as the current is $0 \mathrm{~A}$. Besides, the vertical amplitude decreases and horizontal amplitude increases gradually with the increase of the currents. As the current is $750 \mathrm{~A}$, the vertical amplitude is smaller than the horizontal one, and the motion traces of the two subconductors are both like a horizontal ellipse, but they are different. Therefore, it is concluded that the electromagnetic force has a significant influence on the motion traces of the iced twin bundle conductor transmission line, and it will be taken into account in the next research. 

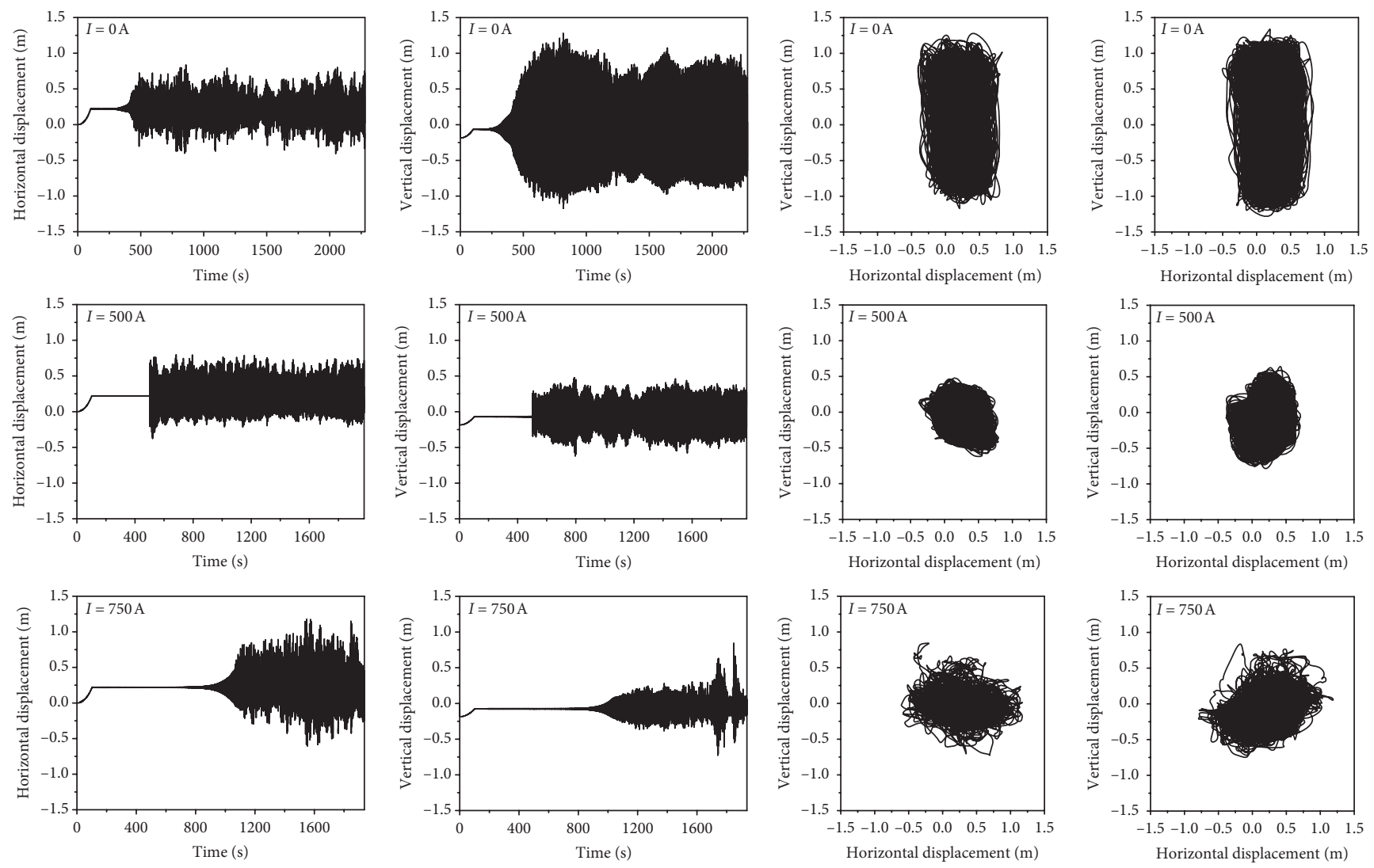

(a)

(b)

(c)

(d)

Figure 10: Time histories of displacement on subconductor 1 and motion traces of two subconductors at a subspan 3 midpoint under different currents $\left(\alpha=30^{\circ}\right.$ ): (a) horizontal displacement of subconductor 1, (b) vertical displacement of subconductor 1, (c) motion traces of subconductor 1 , and (d) motion traces of subconductor 2 .

TABLE 4: Oscillation RMS amplitudes at each subspan midpoint of two subconductors. $\left(\alpha=30^{\circ}\right)$.

\begin{tabular}{|c|c|c|c|c|c|}
\hline \multirow{2}{*}{ Current intensity (A) } & \multirow{2}{*}{ Subspan } & \multicolumn{2}{|c|}{ Horizontal displacement (m) } & \multicolumn{2}{|c|}{ Vertical displacement (m) } \\
\hline & & Subconductor 1 & Subconductor 2 & Subconductor 1 & Subconductor 2 \\
\hline \multirow{4}{*}{0} & 1 & 0.102 & 0.216 & 0.331 & 0.271 \\
\hline & 2 & 0.343 & 0.347 & 1.469 & 1.690 \\
\hline & 3 & 0.341 & 0.350 & 1.471 & 1.689 \\
\hline & 4 & 0.101 & 0.213 & 0.331 & 0.271 \\
\hline \multirow{4}{*}{500} & 1 & 0.258 & 0.258 & 0.177 & 0.186 \\
\hline & 2 & 0.472 & 0.474 & 0.444 & 0.557 \\
\hline & 3 & 0.479 & 0.479 & 0.447 & 0.555 \\
\hline & 4 & 0.257 & 0.259 & 0.180 & 0.185 \\
\hline \multirow{4}{*}{750} & 1 & 0.192 & 0.211 & 0.131 & 0.165 \\
\hline & 2 & 0.445 & 0.435 & 0.237 & 0.326 \\
\hline & 3 & 0.441 & 0.433 & 0.238 & 0.327 \\
\hline & 4 & 0.190 & 0.211 & 0.130 & 0.166 \\
\hline
\end{tabular}

The RMS (root mean square) values of the displacement amplitudes at the midpoint of each subspan are listed in Table 4. It is known that the vibration displacement amplitudes of the subspans near the ends are smaller than those of the middle subspans, and the vertical displacement amplitudes of two subconductors have an obvious difference under all of the given currents. In addition, the vibration amplitudes change greatly under different currents. It can be concluded that the electromagnetic force has a significant influence on the vibration amplitudes of the iced transmission line.

The frequency spectra of the displacements at the midpoint of subspan 3 under different current intensities are shown in Figure 11. According to Figure 11, it can be seen that the spectra peaks of the horizontal displacement appear at $0.335 \mathrm{~Hz}, 0.455 \mathrm{~Hz}$, and $0.667 \mathrm{~Hz}$ and approach the 

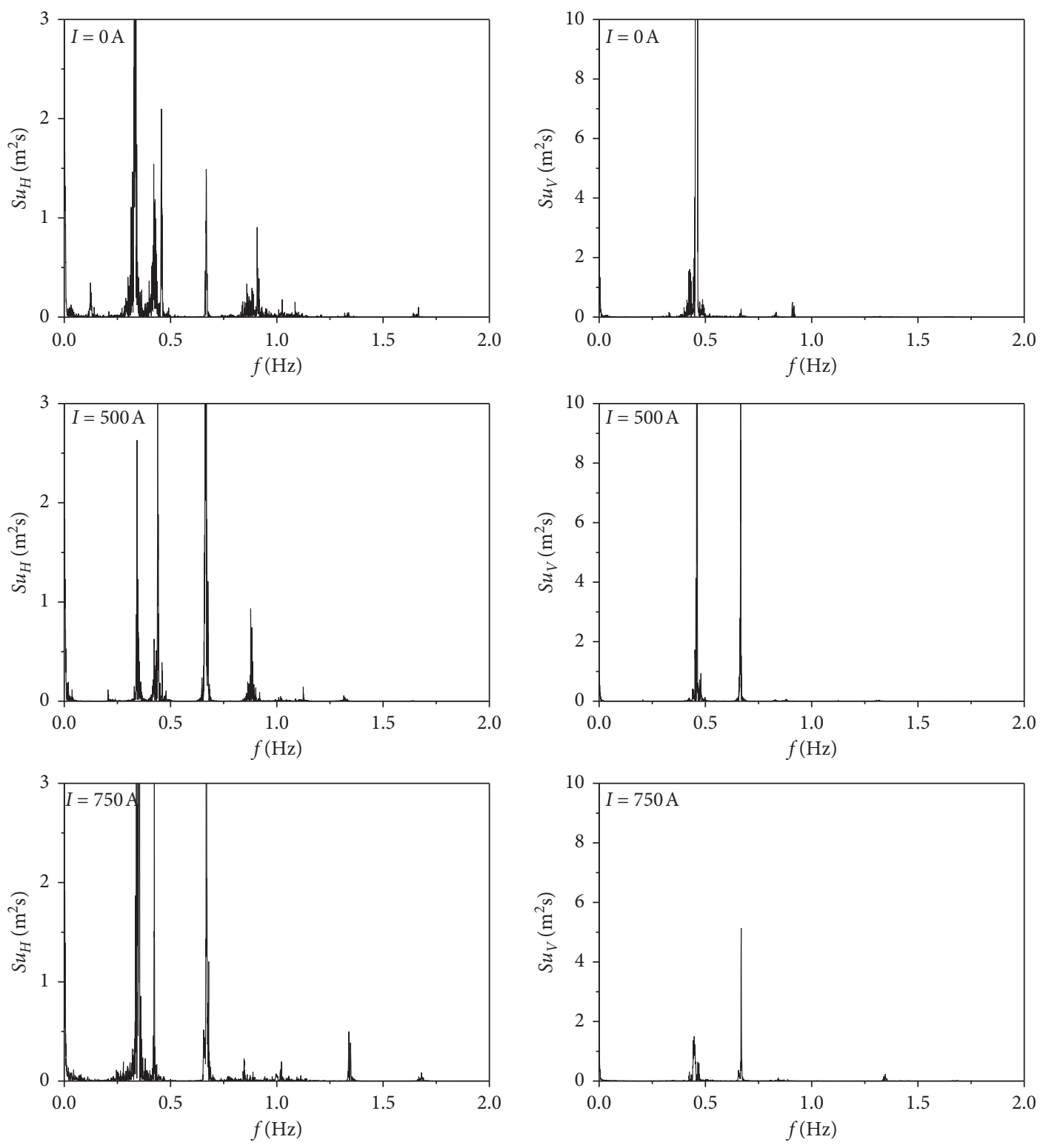

(a)

(b)

FIgURE 11: Displacement spectra at the subspan 3 midpoint of subconductor 1 under different current intensities $\left(\alpha=30^{\circ}\right)$ : (a) horizontal displacement and (b) vertical displacement.

frequencies of the global one-loop out-of-plane, one-loop inplane, and two-loop out-of-plane modes, respectively. Thus, the one-loop and two-loop vibration are the main horizontal vibrations, and the horizontal vibration is influenced by the vertical one-loop vibration. It is also noted that many peaks appear around $1.0 \mathrm{~Hz}$, which may be close to the frequencies of three-loop out-of-plane and first local modes. It indicated that the three-loop and sub-span vibration may appear in the horizontal direction. In addition, as the current is $0 \mathrm{~A}$, the peak of the vertical displacement spectra approaches the frequency $0.475 \mathrm{~Hz}$ of the one-loop in-plane mode; as the current is $500 \mathrm{~A}$, the peaks are close to the frequencies $0.475 \mathrm{~Hz}$ of one-loop in-plane and $0.667 \mathrm{~Hz}$ of two-loop inplane modes; as the current is $750 \mathrm{~A}$, the peak is close to the frequency $0.667 \mathrm{~Hz}$ of the two-loop in-plane mode. The results obtained above manifest that the electromagnetic force has a great effect on the galloping oscillation type, especially on vertical vibration.

It can be known from above that the subspan vibration may take place on the line, so it is necessary to study the change in the distance between two sub-conductors. The time histories of distance at subspan 3 under different currents are illustrated in Figure 12, from which it can be concluded that the distance between two subconductors varies with time. This shows that the consideration of the aerodynamic coefficients varying with the relative position between two subconductors is essential and correct. The minimum distances between two subconductors at the 


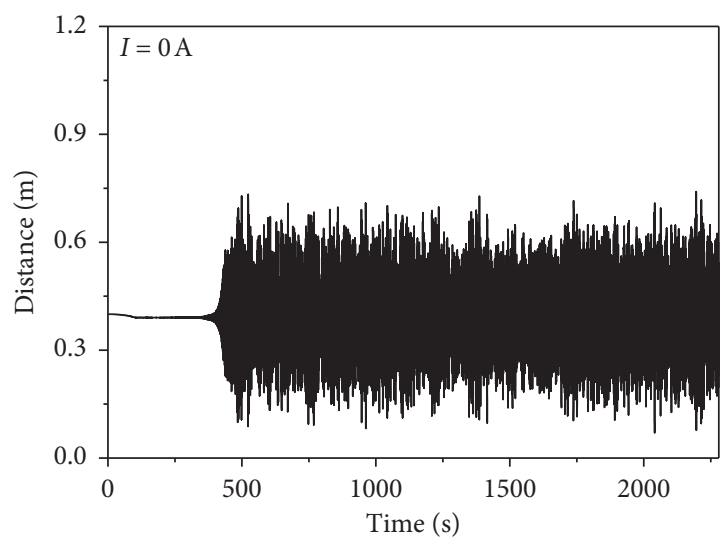

(a)

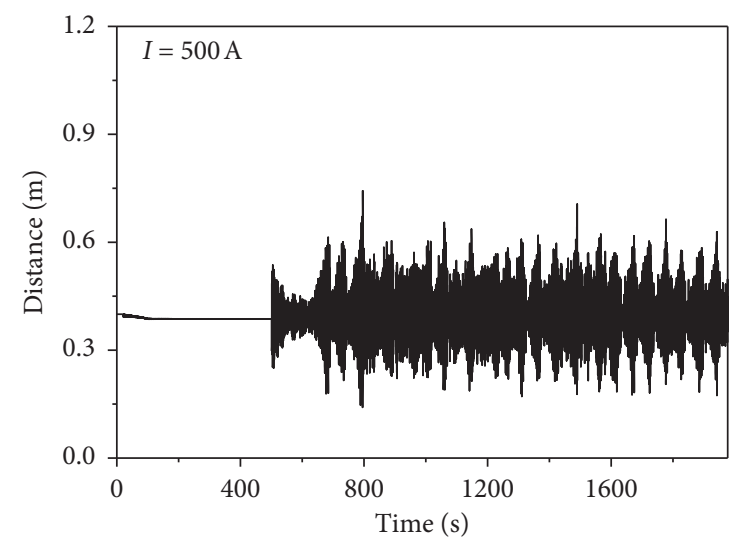

(b)

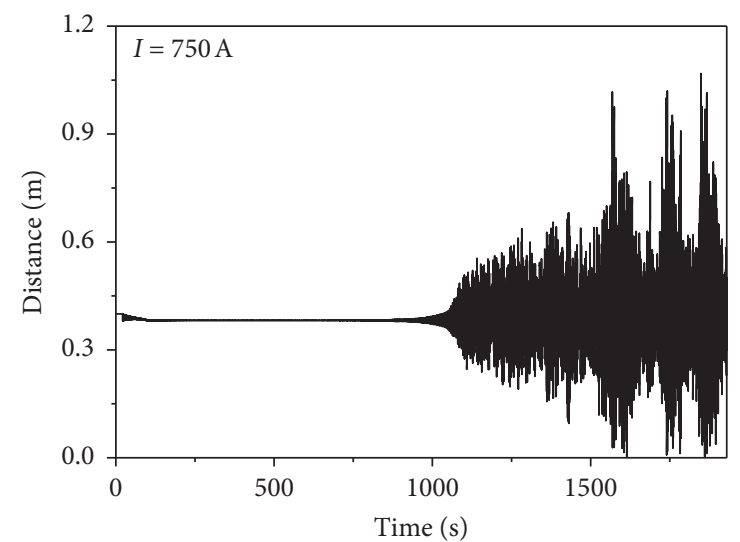

(c)

Figure 12: Time histories of distance at the subspan 3 midpoint between two subconductors under different currents $\left(\alpha=30^{\circ}\right)$ : $($ a $) I=0$ A, (b) $I=500 \mathrm{~A}$, and (c) $I=750 \mathrm{~A}$.

TABLE 5: The minimum distance at each subspan midpoint between two subconductors during the motion process $\left(\alpha=30^{\circ}\right)$.

\begin{tabular}{lcccc}
\hline $\begin{array}{l}\text { Current intensity } \\
\text { (A) }\end{array}$ & \multicolumn{4}{c}{ Minimum distance (m) } \\
\hline 0 & Subspan 1 & Subspan 2 & Subspan 3 & Subspan 4 \\
500 & 0.023 & 0.068 & 0.071 & 0.029 \\
750 & 0.293 & 0.167 & 0.141 & 0.243 \\
\hline
\end{tabular}

midpoint of each subspan with different currents are listed in Table 5. Based on the results, the minimum distances for all subspans are less than $0.0276 \mathrm{~m}$, namely, the diameter of the subconductor, as the current is $750 \mathrm{~A}$. It suggests that two subconductors collide at this time during the oscillation. In this case, the electromagnetic force per unit length is $12.453 \mathrm{~N}$ under a current intensity of $750 \mathrm{~A}$, whereas the aerodynamic lift and drag forces per unit length are $1.697 \mathrm{~N}$ and $0.996 \mathrm{~N}$, respectively. The electromagnetic force is much larger than the aerodynamic forces. It is necessary to consider the effects of the electromagnetic force. Moreover, the typical motion states at a moment of an iced twin bundle conductor during galloping oscillation under different current intensity are shown in Figure 13. According to Figure 14, it can be seen that the vibration types of two subconductors are different, and whole span and subspan vibration take place at the same time.

4.3.2. Effect of Wind Attack Angle. The galloping oscillations of the iced $200 \mathrm{~m}$ span line with a symmetric spacer layout under different wind attack angles of $30^{\circ}$ and $-35^{\circ}$ were studied. The current is assumed as $500 \mathrm{~A}$. The oscillation RMS amplitudes at each subspan with wind attack angles of $30^{\circ}$ and $-35^{\circ}$ are, respectively, shown in Tables 5 and 6 . By comparing the results in two tables, it can be known that vibration displacement amplitudes of the subspans close to the ends are less than those of the middle subspans for these two cases. Besides, the vertical amplitudes of the middle subspans are close for these two cases, and the horizontal amplitudes of the middle subspans under the wind attack angle of $-35^{\circ}$ are much larger than those under the wind attack angle of $30^{\circ}$. The minimum distances at the midpoint of each subspan between two subconductors under the wind attack angle of $-35^{\circ}$ are listed in Table 7 , from which it can be concluded that the minimum distances for all subspans are less than $0.0276 \mathrm{~m}$. It indicates that two subconductors collide with each other, while the collision does not take place under the wind attack angle of $30^{\circ}$, as in Table 5. Thus, the initial wind attack angle has an obvious effect on the 


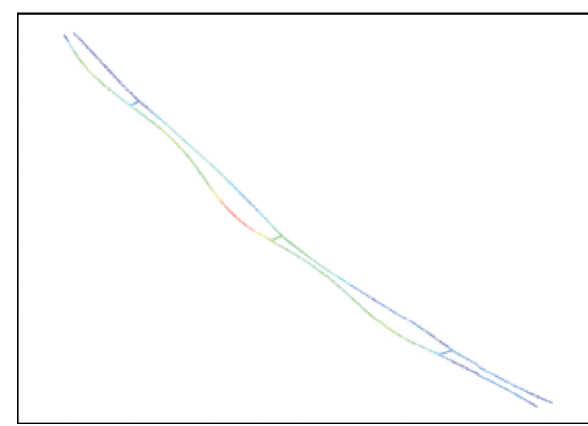

(a)

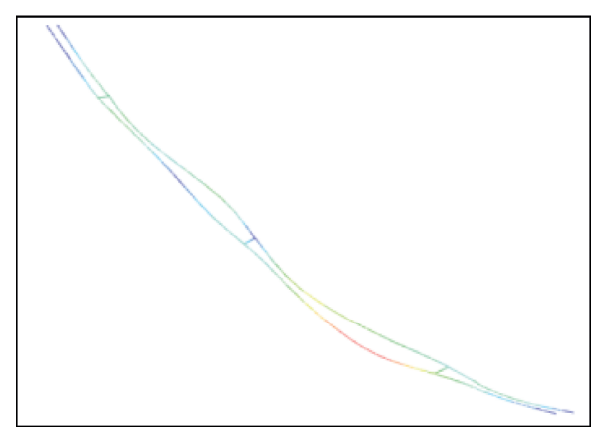

(b)

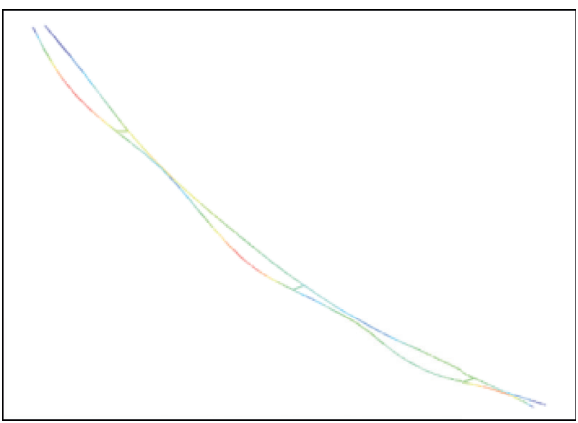

(c)

FIGURE 13: The typical motion state at a moment of an iced twin bundle conductor under different current intensities $\left(\alpha=30^{\circ}\right)$ : (a) $I=0 \mathrm{~A}$, (b) $I=500 \mathrm{~A}$, and (c) $I=750 \mathrm{~A}$.
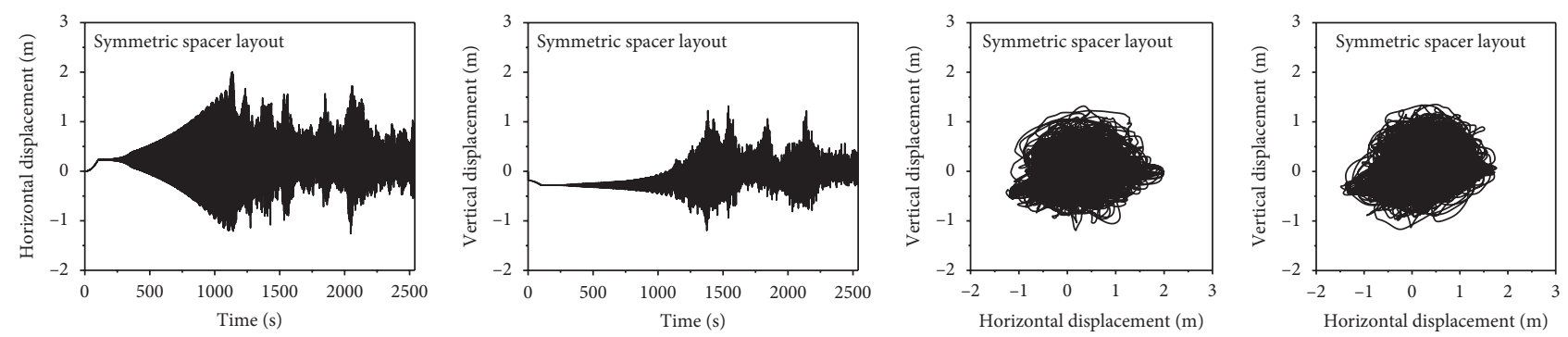

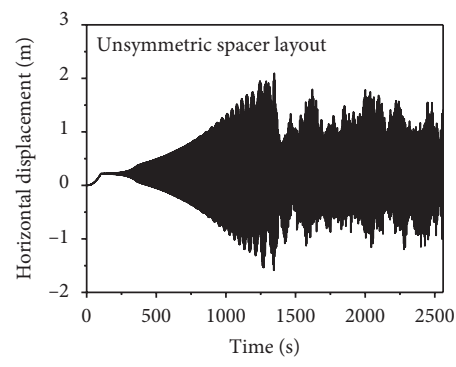

(a)

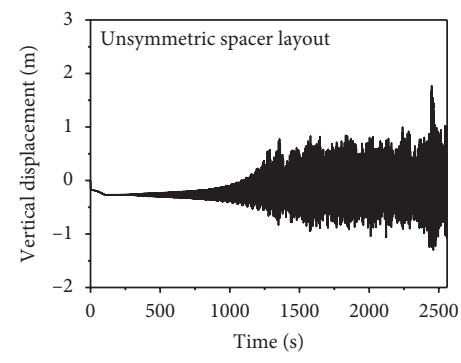

(b)

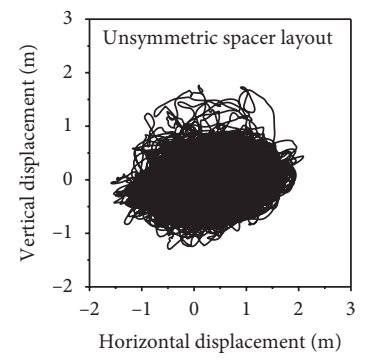

(c)

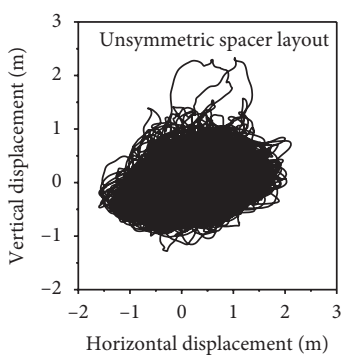

(d)

Figure 14: Time histories of displacement on subconductor 1 and motion traces of two subconductors at the subspan 3 midpoint of the line with an unsymmetric spacer layout $\left(I=500 \mathrm{~A} \alpha=-35^{\circ}\right)$ : (a) horizontal displacement of subconductor 1 , (b) vertical displacement of subconductor $1,(\mathrm{c})$ motion traces of subconductor 1 , and (d) motion traces of subconductor 2 .

galloping oscillation behavior, especially on the vibration amplitudes and distance between two subconductors of the iced transmission line.

4.3.3. Effect of the Spacer Layout Scheme. The galloping oscillations of the $200 \mathrm{~m}$ span line with unsymmetric and symmetric spacer layouts were investigated. It is assumed that the current is $500 \mathrm{~A}$ and wind attack angle is $-35^{\circ}$. Figure 14 shows the time histories of displacement and motion traces at the subspan 3 midpoint with two spacer layouts. It can be known that the horizontal amplitudes are both greater than vertical amplitudes and the motion 
TABLE 6: Oscillation amplitudes at each subspan midpoint between two subconductors under the wind attack angle of $-35^{\circ}(I=500 \mathrm{~A})$.

\begin{tabular}{cccccc}
\hline \multirow{2}{*}{ Wind attack angle $\left(^{\circ}\right)$} & \multirow{2}{*}{ Subspan } & \multicolumn{2}{c}{ Horizontal displacement (m) } & \multicolumn{2}{c}{ Vertical displacement (m) } \\
& & Subconductor 1 & Subconductor 2 & Subconductor 1 & Subconductor 2 \\
\hline & 1 & 0.4640 & 0.4848 & 0.4694 & 0.5281 \\
-35 & 2 & 0.9750 & 0.9948 & 0.4780 & 0.5363 \\
& 3 & 0.9714 & 0.9872 & 0.4833 & 0.5405 \\
& 4 & 0.4614 & 0.4840 & 0.4671 & 0.5282 \\
\hline
\end{tabular}

TABLE 7: The minimum distances at each subspan midpoint between two subconductors under the wind angle $-35^{\circ}$ of attack $(I=500 \mathrm{~A})$.

\begin{tabular}{lcccc}
\hline Wind angle of attack $\left(^{\circ}\right)$ & \multicolumn{4}{c}{ Minimum distance (m) } \\
& Subspan 1 & Subspan 2 & Subspan 3 & Subspan 4 \\
\hline-35 & 0.001 & 0.001 & 0.001 & 0.003 \\
\hline
\end{tabular}

TABLE 8: Oscillation amplitudes at each subspan midpoint of two subconductors. $\left(I=500 \mathrm{~A}, \alpha=-35^{\circ}\right)$.

\begin{tabular}{lccccc}
\hline \multirow{2}{*}{ Spacer layout } & \multirow{2}{*}{ Subspan } & \multicolumn{2}{c}{ Horizontal displacement $(\mathrm{m})$} & \multicolumn{2}{c}{ Vertical displacement (m) } \\
& & Subconductor 1 & Subconductor 2 & Subconductor 1 & Subconductor 2 \\
\hline \multirow{3}{*}{ Unsymmetric } & 1 & 0.7597 & 0.7680 & 0.4554 & 0.5003 \\
& 2 & 1.2659 & 1.2794 & 0.6169 & 0.6799 \\
& 3 & 1.3168 & 1.3332 & 0.7451 & 0.8044 \\
& 4 & 0.6089 & 0.6185 & 0.3583 & 0.3843 \\
\hline
\end{tabular}
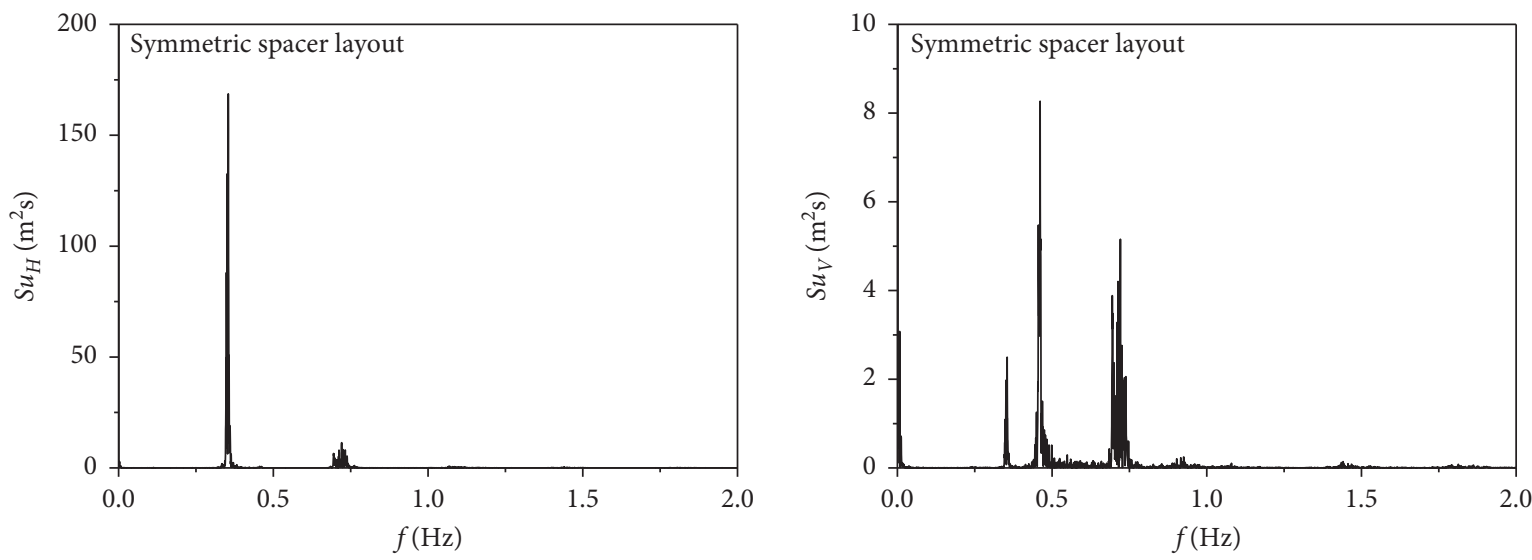

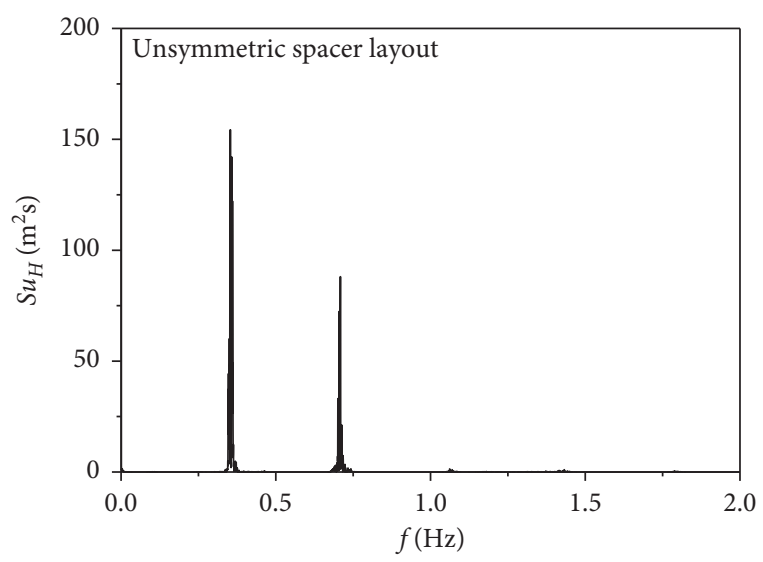

(a)

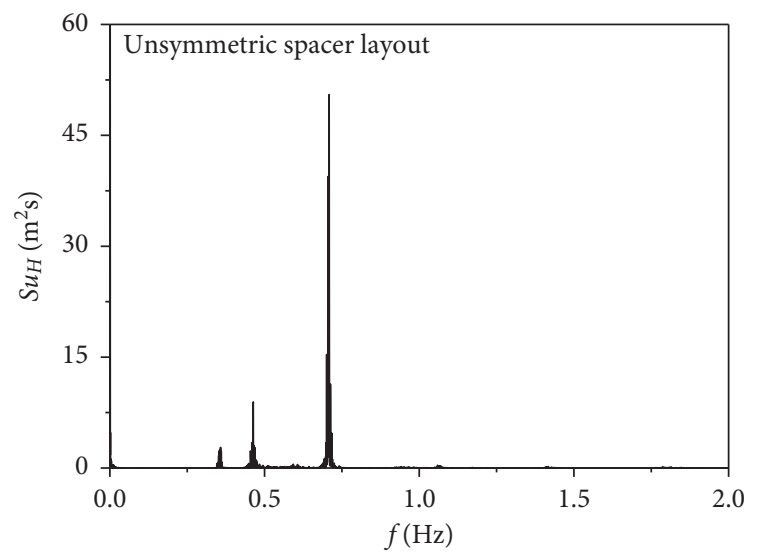

(b)

FiguRE 15: Displacement spectra at the subspan 3 midpoint of subconductor 1 under different current intensities $\left(I=500 \mathrm{~A}, \alpha=-35^{\circ}\right):(\mathrm{a})$ horizontal displacement and (b) vertical displacement. 
TABLE 9: The minimum distance at each subspan midpoint between two subconductors $\left(I=500 \mathrm{~A}, \alpha=-35^{\circ}\right)$.

\begin{tabular}{lcccc}
\hline \multirow{2}{*}{ Spacer layout } & \multicolumn{4}{c}{ Minimum distance (m) } \\
& Subspan 1 & Subspan 2 & Subspan 3 & Subspan 4 \\
\hline Unsymmetric & 0.004 & 0.003 & 0.002 & 0.006 \\
\hline
\end{tabular}

traces both like a vertical ellipse for these two cases. Moreover, the line with an unsymmetric layout has a more stable vibration than the line with a symmetric spacer layout, especially for the vertical vibration. It also can be seen from Table 8 that the oscillation amplitudes of the line with an unsymmetric spacer layout are larger than those of the line with a symmetric spacer layout listed in Table 6.

By analyzing the frequency spectra of the displacements shown in Figure 15, the following results can be obtained. The peak of horizontal displacement spectra appears at $0.357 \mathrm{~Hz}$ which is close to the frequency $0.341 \mathrm{~Hz}$ of the oneloop out-of-plane mode. For the line with a symmetric spacer layout, the spectra peaks of vertical displacement occur at $0.461 \mathrm{~Hz}$ and $0.727 \mathrm{~Hz}$, which approach the frequency $0.476 \mathrm{~Hz}$ of one-loop and $0.680 \mathrm{~Hz}$ of two-loop inplane modes, respectively. However, for the line with an unsymmetric spacer layout, the spectra peaks of horizontal displacement appear at $0.357 \mathrm{~Hz}$ and $0.710 \mathrm{~Hz}$, which, respectively, approach the frequency $0.340 \mathrm{~Hz}$ of one-loop and $0.678 \mathrm{~Hz}$ of two-loop out-of-plane modes. The peak of vertical displacement spectra appear at $0.711 \mathrm{~Hz}$ close to the frequency $0.676 \mathrm{~Hz}$ of two-loop in-plane mode. It is noted that some small frequency peaks also exist around $1.0 \mathrm{~Hz}$, as discussed in Section 4.3.1. Therefore, the main vibrations in the horizontal and vertical direction of the line with the unsymmetric and symmetric spacer layouts are different, indicating that the spacer layout has a significant effect on the galloping vibration type. Additionally, it can be known from Table 9 that the minimum distances for all subspans are less than $0.0276 \mathrm{~m}$, suggesting that two subconductors collide with each other.

\section{Conclusions}

The numerical simulation method of the aerodynamic coefficients is verified to be feasible and accurate by the wind tunnel tests. Then, the aerodynamic coefficients of the iced twin bundle conductors varying with wind attack angle and relative position between two subconductors were simulated. The galloping oscillation behaviors of iced twin bundle conductor transmission lines with the effect of electromagnetic force under different parameters were numerically simulated. The conclusions obtained are as follows.

(1) The aerodynamic characteristics of two subconductors are significantly affected by the wind attack angle, and those of the leeward subconductor are obviously influenced by the wake of the windward one

(2) The electromagnetic force between the subconductors may has a great impact on the galloping oscillation of the iced twin bundle conductor transmission line, and the motion traces of the iced $200 \mathrm{~m}$ span line change from a vertical ellipse to a horizontal ellipse as the current intensity increases

(3) The whole-span and subspan vibration may appear at the same time during galloping oscillation, and two subconductors may collide with each other under the effect of the varying electromagnetic and aerodynamic forces

(4) For the iced twin bundle conductor transmission line with $200 \mathrm{~m}$ span, the initial wind attack angle has an obvious effect on the main vibration mode and the minimum distance between two subconductors, and the spacer layout can affect, significantly, the vibration amplitudes and the main vibration mode of the line

\section{Data Availability}

The data used to support the findings of this study are available from the corresponding author upon request.

\section{Conflicts of Interest}

The authors declare that there are no conflicts of interest regarding the publication of this paper.

\section{Acknowledgments}

This work was supported in part by the Science and Technology Project of State Grid Corporation of China (52170218000F) and China Postdoctoral Science Foundation Funded Project (2020M672238).

\section{References}

[1] S. Dmitry, Wake-Induced Oscillations in Cable Structures: Finite Element Approach, University of Liege, Moscow, Russia, 2010.

[2] A. Zhou, X. Liu, S. Zhang, F. Cui, and P. Liu, "Wind tunnel test of the influence of an interphase spacer on the galloping control of iced eight-bundled conductors," Cold Regions Science and Technology, vol. 155, pp. 354-366, 2018.

[3] G. Li and L. Li, "Effect of temperature on galloping of iced conductors," Advances in Structural Engineering, vol. 21, no. 1, pp. 3-13, 2018.

[4] H. Matsumiya, T. Nishihara, and T. Yagi, "Aerodynamic modeling for large-amplitude galloping of four-bundled conductors," Journal of Fluids and Structures, vol. 82, pp. 559-576, 2018.

[5] Q. Zhang, N. Popplewell, and A. H. Shah, "Galloping of bundle conductor," Journal of Sound and Vibration, vol. 234, no. 1, pp. 115-134, 2000.

[6] E. Taib, J. H. Shin, M. K. Kwak, and J. R. Koo, "Dynamic modeling and simulation for transmission line galloping," Journal of Mechanical Science and Technology, vol. 33, no. 9, pp. 1-9, 2019.

[7] J. Hu, B. Yan, S. Zhou, and H. Zhang, "Numerical investigation on galloping of iced quad bundle conductors," IEEE Transactions on Power Delivery, vol. 27, no. 2, pp. 784-792, 2012. 
[8] B. Yan, X. Liu, X. Lv, and L. Zhou, "Investigation into galloping characteristics of iced quad bundle conductors," Journal of Vibration and Control, vol. 22, no. 4, pp. 965-987, 2016.

[9] L. Zhou, B. Yan, L. Zhang, and S. Zhou, "Study on galloping behavior of iced eight bundle conductor transmission lines," Journal of Sound and Vibration, vol. 362, pp. 85-110, 2016.

[10] J. Lu, Q. Wang, L. Wang et al., "Study on wind tunnel test and galloping of iced quad bundle conductor," Cold Regions Science and Technology, vol. 160, pp. 273-287, 2019.

[11] W. Lou, C. Huang, M. Huang, and J. Yu, "An aerodynamic anti-galloping technique of iced 8-bundled conductors in ultra-high-voltage transmission lines," Journal of Wind Engineering and Industrial Aerodynamics, vol. 193, Article ID 103972, 2019.

[12] S. J. Price, "Wake induced flutter of power transmission conductors," Journal of Sound and Vibration, vol. 38, no. 1, pp. 125-147, 1975.

[13] C. B. Rawlins, "Fundamental concepts in the analysis of wakeinduced oscillation of bundled conductors," IEEE Transactions on Power Apparatus and Systems, vol. 95, no. 4, pp. 1377-1393, 1976.

[14] S. Tokoro, H. Komatsu, M. Nakasu, K. Mizuguchi, and A. Kasuga, "A study on wake-galloping employing full aeroelastic twin cable model," Journal of Wind Engineering and Industrial Aerodynamics, vol. 88, no. 2-3, pp. 247-261, 2000.

[15] A. L. Braun and A. M. Awruch, "Aerodynamic and aeroelastic analysis of bundled cables by numerical simulation," Journal of Sound and Vibration, vol. 284, no. 1-2, pp. 51-73, 2005.

[16] G. Diana, M. Belloli, S. Giappino et al., "A numerical approach to reproduce subspan oscillations and comparison with experimental data," IEEE Transactions on Power Delivery, vol. 29, no. 3, pp. 1311-1317, 2014.

[17] G. Diana, M. Belloli, S. Giappino et al., "Wind tunnel tests on two cylinders to measure subspan oscillation aerodynamic forces," IEEE Transactions on Power Delivery, vol. 29, no. 3, pp. 1273-1283, 2014.

[18] M. Cai, B. Yan, X. Lu, and L. S. Zhou, "Numerical simulation of aerodynamic coefficients of iced-quad bundle conductors," IEEE Transactions on Power Delivery, vol. 30, no. 4, pp. 1669-1676, 2015.

[19] P. Spalart and S. Allmaras, "A one-equation turbulence model for aerodynamic flows," La Recherche Aérospatiale, vol. 439, no. 1, pp. 5-21, 1992.

[20] C. Wu, B. Yan, G. Huang, B. Zhang, Z. Lv, and Q. Li, "Wakeinduced oscillation behaviour of twin bundle conductor transmission lines," Royal Society Open Science, vol. 5, no. 6, Article ID 180011, 2018.

[21] P. Mehta and R. Swart, "Generalized formulation for electromagnetic forces on current-carrying conductors," IEEE Transactions on Power Apparatus and Systems, vol. PAS-86, no. 2, pp. 155-166, 1967.

[22] J. L. Lilien, State of the Art of Conductor Galloping, International Council on Large Electric systems, Paris, France, 2005.

[23] Ministry of Construction of the People's Republic of China (MCPRC), GB50017-2003 Code for Steel Structure Design, China Planning Press, Beijing, China, 2003.

[24] G. H. Koopman, "The vortex wakes of vibration cylinders at low Reynolds numbers," Journal of Fluid Mechanics, vol. 28, no. 3, pp. 501-512, 1967. 